\title{
A Decade of Porous Silicon as Nano-Explosive Material
}

\author{
Monuko du Plessis
}

\begin{abstract}
It is a decade since the accidental discovery of the room temperature explosive properties of porous silicon, impregnated with a solid state oxidizer, was communicated in 2002 [1]. A significant amount of research and development have followed this announcement, leading to an innovative explosive technology that may be on the verge of being applied in a number of applications. It is thus now an opportune time to reflect on the progress of this new technology over the last decade. Just in the last two years, there has been a significant increase in the number of research papers reporting on new developments and exciting new applications. In this paper the
\end{abstract}

technological development of porous silicon explosive devices is reviewed, a decade of technological research and development documented, and the current state of the technology evaluated. The most important aspects of the technology are presented, device performance characteristics are investigated and different applications are considered. Typical device design and manufacturing techniques are highlighted that actually resulted in reliable explosive behavior. The information in this paper should serve as a source of reference not only for researchers already active in this field, but also to new researchers starting or contemplating to exploit this technology.

Keywords: Nanotechnology, Porous Silicon, Energetic Material

\section{Introduction}

The silicon integrated circuit semiconductor technology is a very mature and well-established technology following the well-known Moore's law for decades. Integrated circuits with more than 1 billion active devices can relatively easily be manufactured using nanoscale technology. As the technology dimensions are shrunk down even further, there is a view that the future of the silicon-based technology will have to be "more than Moore" rather than "more of Moore". This means that more functionality will have to be integrated onto the chip, and not just more electronic circuitry. These "silicon derivatives" include photonic devices, MEMS (Micro Electro-Mechanical Systems) and MOEMS (Micro Optical-Electrical-Mechanical Systems), as well as biological interfaces, e.g. micro fluidics. For all of the new functionalities to be successfully integrated into the integrated circuit technology, the technological impact should be as low as possible, due to the large investment made in CMOS (Complementary Metal-Oxide Semiconductor) fabrication facilities. The economic success of any new functionality depends on the ease of fabrication of devices using the existing IC (Integrated Circuit) processes. Since the discovery of the porous silicon electrochemical etch technique, several such new functionalities and applications have been investigated, one of which is the use of porous silicon as an energetic material.

Energetic materials store chemical energy and can be classified into different classes, i.e., propellants, explosives, and pyrotechnics [2]. Propellants and pyrotechnics release their energy through relatively slow deflagration processes while explosives release their energy in fast detonation processes. Traditional energetic materials are produced by the following two techniques: 1) the mixing of oxidizer and fuel constituents into one molecule to produce monomolecular energetic materials, e.g. TNT (TriNitroToluene), or 2) the mixing of oxidizer powders (e.g. nitrates or perchlorates) and fuel powders (e.g. carbon) to produce composite energetic materials. These composites exhibit high energy density, but their energy release rates are slower because the mass transport rate is limited by the granulometry of the reactants. Reducing the particle size to the nanoscale will result in reduction of the mass-transport rate and would increase the burning rates, making nanoscale energetic materials attractive alternatives to monomolecular structures. Nanoporous silicon filled with an oxidizer is a promising nanostructured method to realize an energetic material which is compatible with silicon process technology [2]. The oxidation of silicon involves two steps, namely the diffusion of oxygen through the oxide layer followed by the first-order (linear) oxidation of silicon at the $\mathrm{Si}^{-} \mathrm{SiO}_{2}$ interface [3]. The bulk silicon oxidation rate is limited by the slow diffusion of oxygen through the silicon dioxide layer at the silicon surface according to the classical Deal and Grove oxidation model [4].

\footnotetext{
M. du Plessis

Department of Electrical, Electronic and Computer

Engineering

Carl and Emily Fuchs Institute for Microelectronics

University of Pretoria

Pretoria 0002, South Africa

Fax: (+27) 123625115

E-mail:monuko@up.ac.za
} 
This oxidation model does not adequately describe the initial phase of oxidation of nanoparticles. In a study of the oxidation of $10 \mathrm{~nm}$ diameter silicon nanoparticles it was found that the first-order linear oxidation constant $k_{0}$, with units $\mathrm{m} \mathrm{s}^{-1}$, was a factor 1500 higher for the nanoparticles than for bulk silicon [3]. This high initial oxidation rate, combined with the large specific surface area of the porous silicon structure, result in the potential yield of energy of the exothermic reaction of silicon and oxygen to be higher than that of the most common carbon-based explosives. Porous silicon has the necessary nanoscale morphological properties which are crucial for explosive reactions [4].

\section{Early Developments}

The first reference to porous silicon explosive behavior was in 1992 [5]. In this chemiluminescence study of porous silicon it was reported that a "flash of light and an audible pop" were observed when concentrated $\mathrm{HNO}_{3}$ was dropped on the surface of dry porous silicon. Concentrated $\mathrm{H}_{2} \mathrm{SO}_{4}$ did not induce the same reaction, and furthermore only the porous silicon produced by the anodization method showed this violent reaction. This was a first indication that the type of oxidizer, as well as the morphology and chemical structure of the porous silicon, will determine the explosive behavior of the material. Another explosive observation was reported in 1994, however, in this case not using porous silicon, but rather silicon nanoparticles [6]. The silicon nanoparticles were prepared from the powder growth as a result of the mixing of silane and oxygen gases, with particle sizes varying from $7 \mathrm{~nm}$ to $20 \mathrm{~nm}$. Applying a drop of full strength concentrated nitric acid to these silicon nanoparticles resulted in a "bright flash of light", likewise reported for siloxene and porous silicon [5], after which the silicon particles could still be seen.

It took almost a decade before the next report on explosive porous silicon appeared in 2001, when it was reported that nano-explosions could be accomplished at cryogenic temperatures [7]. A new type of chain reaction was reported which proceeded explosively after the filling of pores of hydrogenterminated porous silicon by condensed or liquid oxygen in the temperature range of $4.2 \mathrm{~K}$ to $90 \mathrm{~K}$. About $20 \%$ of the silicon atoms are located at the surface of the nanocrystals for high specific surface area devices, and when freshly prepared, the internal surface of porous silicon is almost completely covered by hydrogen whose atomic content can be as high as $10^{22} \mathrm{~cm}^{-3}$ [8]. It was experimentally shown that the level of hydrogen accumulation in porous silicon is in the range of $60 \mathrm{mmol}$ hydrogen per gram of porous silicon, or 6 mass \%, that corresponds to a $\mathrm{H} / \mathrm{Si}$ ratio of about 1.8 [9]. Therefore, hydrogen-terminated porous silicon serves as a reservoir of hydrogen. In the temperature range $4.2 \mathrm{~K}$ to $90 \mathrm{~K}$ both the adsorptive condensation of gaseous oxygen inside the hydrogenterminated pores of porous silicon and the immersion of the porous layer in liquid oxygen resulted in a strong explosion [7]. Furthermore, the explosive reaction was absent if silicon nanocrystals assembling the porous layers were completely oxygen terminated. Therefore, both the filling of pores by liquid oxygen and the termination of the surface of $\mathrm{Si}$ nanocrystals by hydrogen seemed to be crucial for the explosive reaction.

A major breakthrough was reported in 2002, a decade ago, after the accidental discovery of a nanoexplosion in porous silicon impregnated with a solid state oxidizer at room temperature [1]. Researchers had a chip blow up after scratching a porous silicon wafer that had been impregnated with gadolinium nitrate. Addition of the oxidizing agent as a dilute nitrate salt solution (instead of the liquid agents used previously) allowed the preparation of a solid material that could be ignited in a more controlled fashion. The nitrate-treated, dried samples exploded when scratched with a diamond scribe or when subjected to a small electric spark. Samples that contained a large amount of surface oxide (as determined by Fourier transform infrared spectroscopy, FTIR) were usually not explosive. Qualitatively, increased nitrate levels produced a more intense explosion. This accidental discovery of a nano-explosion in porous silicon at room temperature was reported and commented on quite extensively in the popular engineering press, e.g. "Silicon-based gunpowder may propel MEMS devices" [10], and "Chip provides more bang" [11].

\section{Porous Silicon Preparation}

Nano-explosive devices are based on porous silicon prepared using an electrochemical etch technique, usually in a HF:Ethanol electrolyte. The pores of the porous region are impregnated with an oxidizer, and when heat or energy is applied to the device, a strong exothermic reaction occurs [12].

\subsection{Porous Silicon Etching and Drying}

Porous silicon can be prepared on both n-type and $p$ type bulk material. From the literature it follows that only the very first realisation of solid state explosive devices made use of $n$-type bulk silicon [1]. In this particular study use was also made of p-type bulk silicon, and it was reported that most porous samples could be exploded, regardless of the crystalline silicon used in terms of $\mathrm{p}$ - or n-type and doping density. Electronic holes are required in the anodisation process to form porous silicon, and in the case of $n$ type silicon where holes are minority carriers, illumination of the sample is needed to photo-generate holes in the sample [13]. No illumination is needed in p-type silicon where holes are majority carriers. Typically a $300 \mathrm{~W}$ tungsten lamp with intensity of $50 \mathrm{~mW} \mathrm{~cm}{ }^{-2}$ provides sufficient illumination during the electrochemical etch to provide holes in the n-type material to take part in the chemical reaction [1, 14]. All other reports on the use of porous silicon as explosive material used p-type silicon, presumably since the anodization process without illumination is easier. Table 1 tabulates typical porous silicon etch 
parameters for a selected number of references. It is evident that a wide range of etch parameters can be used, with silicon resistivity ranging from $1 \mathrm{~m} \Omega-\mathrm{cm}$ to $20 \Omega-\mathrm{cm}$, and current densities ranging from $18.5 \mathrm{~mA} \mathrm{~cm}^{-2}$ to $100 \mathrm{~mA} \mathrm{~cm}^{-2}$. Table 2 lists typical porous silicon properties used in explosive devices. The porosities are generally higher than $60 \%$, and the pore sizes vary for most applications between $2 \mathrm{~nm}$ and $15 \mathrm{~nm}$.

Table 1. The electrochemical etch parameters of selected explosive devices.

\begin{tabular}{llllll}
\hline Reference & Year & $\mathrm{p} / \mathrm{n}$ type & $\begin{array}{l}\text { Resistivity } \\
\text { ohm-cm }\end{array}$ & $\begin{array}{l}\text { Current density } \\
\mathrm{mA} \mathrm{cm}\end{array}$ & $\begin{array}{l}\text { Electrolyte } \\
\text { HF:Ethanol }\end{array}$ \\
\hline$[1]$ & 2002 & $\mathrm{n}$ & 4 & 50 & $1: 1(49 \% \mathrm{HF})$ \\
{$[4]$} & 2004 & $\mathrm{p}$ & $1 \times 10^{-3}-1$ & $20-87$ & $1: 1(50 \% \mathrm{HF})$ \\
{$[15]$} & 2007 & $\mathrm{p}$ & $0.2-0.3$ & 76.5 & $1.5: 1(50 \% \mathrm{HF})$ \\
{$[16]$} & 2008 & $\mathrm{p}$ & $1-10$ & 20 & $1: 1(25 \% \mathrm{HF})$ \\
{$[17]$} & 2008 & $\mathrm{p}$ & $3-6$ & 22.5 & $1: 1(40 \% \mathrm{HF})$ \\
{$[18]$} & 2009 & $\mathrm{p}$ & $1-5 \times 10^{-3}$ & $60.1-73.4$ & $1: 1(49 \% \mathrm{HF})$ \\
{$[19]$} & 2009 & $\mathrm{p}$ & $1-10$ & 18.5 & $1: 1(49 \% \mathrm{HF})$ \\
{$[20]$} & 2010 & $\mathrm{p}$ & $1-20$ & Galvanic & $3: 1(49 \% \mathrm{HF})$ \\
& & & & & $2.4 \%$ vol of $30 \% \mathrm{H}_{2} \mathrm{O}_{2}$ added \\
{$[21]$} & 2011 & $\mathrm{p}$ & $1-20$ & Galvanic & $3: 1(49 \% \mathrm{HF})$ \\
& & & & & $2.4 \%$ vol of $30 \% \mathrm{H}_{2} \mathrm{O}_{2}$ added \\
{$[22]$} & 2012 & $\mathrm{p}$ & $0.1-0.3$ & 100 & $3: 1(40 \% \mathrm{HF})$ \\
\hline
\end{tabular}

Table 2. The porous silicon properties of selected explosive devices.

\begin{tabular}{lllll}
\hline Reference & Year & $\begin{array}{l}\text { Porosity } \\
\%\end{array}$ & $\begin{array}{l}\text { Pore size } \\
\mathrm{nm}\end{array}$ & $\begin{array}{l}\text { Thickness } \\
\mu \mathrm{m}\end{array}$ \\
\hline$[1]$ & 2002 & & $<1000$ & 25 \\
{$[4]$} & 2004 & $49.3-71$ & & $57-193$ \\
{$[15]$} & 2007 & 65 & 3.4 & 57 \\
{$[16]$} & 2008 & & 4 & 40 \\
{$[17]$} & 2008 & 55.9 & $9.7-14.7$ & 15 \\
{$[18]$} & 2009 & $73-82$ & $10-100$ & $125-141.5$ \\
{$[19]$} & 2009 & 67 & 3.4 & 33 \\
{$[20]$} & 2010 & $62-69$ & $2.65-3.05$ & 156 \\
{$[21]$} & 2011 & $65-83$ & $2.4-2.9$ & $65-95$ \\
{$[22]$} & 2012 & & $2-7$ & $80.6-86.1$ \\
\hline
\end{tabular}

\subsection{Porosity of Porous Silicon}

The porosity of the PSi structure can be adjusted for the finally chosen oxidizer. The highest energy yield of the reaction is assured when the oxidation reaction is complete, which implies a stoichiometric ratio of $\mathrm{SiX}_{2}$, where $X$ is oxygen or sulphur, and can be realized for PSi layers having porosity in the range of $70 \%$ for most of the oxidizers in use [23].

For example, in the case of the oxidizer $\mathrm{NaClO}_{4}$ in its anhydrous and monohydrate forms the reactions will be [24]

Anhydrous:

$$
2 \mathrm{Si}+\mathrm{NaClO}_{4} \rightarrow 2 \mathrm{SiO}_{2}+\mathrm{NaCl}
$$

Monohydrate:

$$
2 \mathrm{Si}+\mathrm{NaClO}_{4} \cdot \mathrm{H}_{2} \mathrm{O} \rightarrow 2 \mathrm{SiO}_{2}+\mathrm{NaCl}+\mathrm{H}_{2} \mathrm{O}
$$

The above equations require a molar ratio of 0.5 sodium perchlorate to silicon for complete oxidation of all the porous silicon. Assuming that the oxidizer completely fills all of the pore volume and that all of the sodium perchlorate will react with all of the silicon, the molar ratio of oxidizer (sodium perchlorate) to fuel (silicon) was computed using the densities and molecular weights of oxidizer and fuel. The oxidizer to fuel molar ratio as a function of porosity is plotted in Figure 1, where it is shown that the minimum porosity required achieving the required 0.5 molar ratio for complete combustion is $70 \%$ for the monohydrate sodium perchlorate, and $72 \%$ for the anhydrous sodium perchlorate. Experimental molar ratios normally lie below these values because the porous structure is not completely filled with the oxidizer [20]. In the best case a pore filling factor of about $75 \%$ was achieved for an oxidizer to fuel molar ratio of 0.3 at $63 \%$ porosity [20]. 


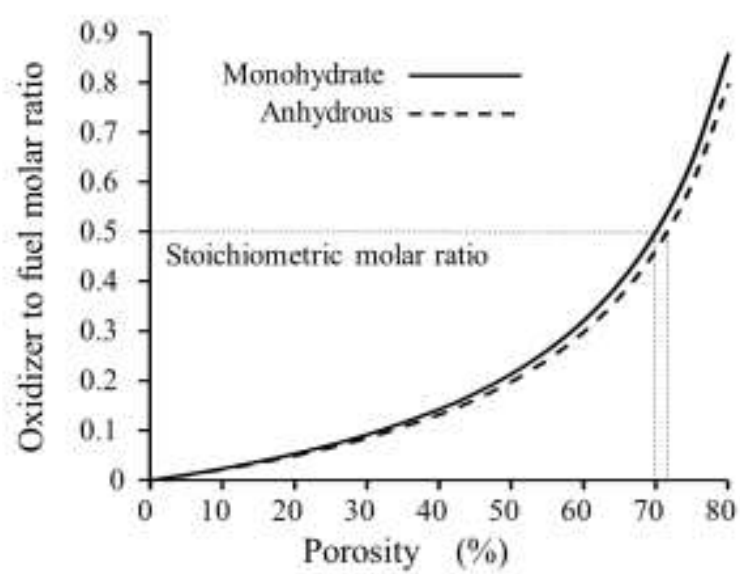

Figure 1. The oxidizer to fuel molar ratio of porous silicon for monohydrate and anhydrous $\mathrm{NaClO}_{4}$ as a function of porous silicon porosity assuming all void space is filled with the oxidizer. The stoichiometric molar ratio of 0.5 is also shown.

At higher current densities the porous layers may become unstable [12]. Two methods can be used to reduce the instability, namely tapering the etch current density and pentane drying. By tapering the etch current density (starting with a high value and reducing the current density over time), a finer pore structure can be realised at the bulk/porous silicon interface, and the porous silicon can be anchored better to the substrate [12].

It was found that under constant etching current conditions porous silicon layers became mechanically unstable after a certain etching time, and the maximum depth of mechanically stable layers achieved was about $200 \mu \mathrm{m}$ [23]. To produce thicker layers a "gradient-break-etching" technique was devised where not only the current density was gradually decreased over time, but in addition breaks in the etching process were inserted to allow hydrogen to be released from the pores and give the etching solution time for concentration equilibration at the front of etching [23]. This technique enabled the preparation of porous layers up to thicknesses of nearly $500 \mu \mathrm{m}$, which can in theory be extended to larger wafers. As another example, using this technique porous silicon samples were etched for a total time of 1 hour consisting of 10 minute etching intervals separated by 3 minute breaks to allow built up hydrogen in the pores to escape [18].

A method well-suited for batch processing is the galvanic corrosion technique in which thick (up to $150 \mu \mathrm{m}$ ) films are prepared without an external power supply [20]. With a chemical oxidant like $\mathrm{H}_{2} \mathrm{O}_{2}$ present in the HF:Ethanol solution a noble metal such as platinum or gold deposited on the silicon serves as a cathode to form a galvanic cell without an external current source. The morphology of the porous silicon can be controlled by the choice of electrolyte composition, oxidizing agent, noble metal, silicon resistivity and silicon dopant type (p-or n-type) in the galvanic set-up.
Drying of the samples after the porous silicon formation can be achieved by rinsing the samples with ethanol or methanol, followed by the drying agent hexane, and also drying it subsequently under a gentle stream of nitrogen $[1,25]$. The samples can also be rinsed using another drying agent, pentane, to ensure the structural stability of the pores [26]. After rinsing the sample in methanol, a thin layer of methanol can be allowed to slowly evaporate, followed by a rinse in pentane [12]. Pentane has a much lower surface tension than either methanol or ethanol, and has been shown to reduce porous silicon cracking during drying.

\subsection{Porous Silicon Surface Stabilization}

Porous silicon layers can have a large internal specific surface area (up to $1000 \mathrm{~m}^{2} \mathrm{~cm}^{-3}$ ), and are assembled from nanocrystals and pores, both nanometer-sized, and therefore the spacing between the fuel (silicon) and the oxidizing atom is at the atomic scale. Ordinary pyrotechnical materials are usually mixed powders pressed together to form pellets, and in this case mixtures of fuel and oxidizer on a molecular scale will not be achieved [23]. For as-prepared samples, the porous silicon internal surface is almost completely covered with hydrogen. Furthermore, about $20 \%$ of the silicon atoms are located at the surface of the nanocrystals [8]. The surface of freshly etched porous silicon is covered with $\mathrm{Si}_{\mathrm{H}} \mathrm{H}_{\mathrm{x}}(\mathrm{x}=1,2,3)$ groups, and during storage the $\mathrm{Si}-\mathrm{H}_{x}$ groups are replaced with $\mathrm{Si}$ $\mathrm{O}_{x}$ groups; i.e. the surface is dehydrogenated [27]. It was demonstrated that the size of the light flash observed in combustion of porous silicon layers decreases with the storage time, and the associated loss of hydrogen during storage, of samples after anodization and impregnation with $\mathrm{KNO}_{3}$. The longest storage time during the experiment was 48 hours. The largest flash was observed for freshly prepared samples [27]. The hydrogen coverage of silicon nanostructures was found to be strongly dependent on the nanoscale morphology [28]. For high porosity values $(>63 \%)$ present in most explosive porous silicon devices, hydrogen is mainly stored under dihydride $\left(\mathrm{Si}-\mathrm{H}_{2}\right)$ complexes. The surfaces of freshly prepared porous silicon samples also have a large number of silicon dangling bonds, and natural aging by oxidation of porous silicon is associated with the formation of a monolayer of oxygen atoms back bonded to the surface silicon layer while the hydrogen atoms covering the surface $\mathrm{Si}$ atoms remain unaffected [29].

To achieve long-term stability, the porous silicon surfaces can be stabilized by thermal annealing of the porous silicon sample in an oxygen atmosphere below $250^{\circ} \mathrm{C}$ [23], almost like an accelerated aging where the oxygen is mainly back bonded to surface silicon atoms, while the hydrogen atoms covering the surface silicon atoms remain unaffected and the porous silicon surface remains organophilic [6]. At higher annealing temperatures, effusion of hydrogen atoms occurs and the oxygen will be bonded directly to the surface, making it more hydrophilic [23]. This annealing at lower temperatures did not influence the 
explosive reactivity of freshly etched samples, but annealing at higher temperatures decreased the efficiency of the reaction. Annealing at temperatures above $300^{\circ} \mathrm{C}$ leads to appearance of strong Si-O bonds and the $\mathrm{Si}-\mathrm{H}$ bands disappear, while annealing at a temperature of $150^{\circ} \mathrm{C}$ leads to the formation of backbonded oxygen, while maintaining the $\mathrm{Si}-\mathrm{H}$ termination. The backbonded oxygen layer lends significant surface stability to the material. The activation energy of the porous silicon/oxygen reaction can be tailored by controlling the native layer before the oxidizer loading [2]. The explosive reactivity of the material decreases as the level of oxidation increases and can be used to tailor it. Partial or complete oxidation of the surface can also render porous siliconoxidizer mixtures less sensitive to friction and impact [30].

A process step to ensure a complete coverage of hydrogen atoms at the silicon surface was proposed, namely that the freshly electrochemically etched porous silicon be dipped in a solution of HF and ethanol [31]. This removed the thin oxygen layer formed after exposure to air and re-saturated the dangling bonds at the surface with hydrogen. This hydrogen cover of a silicon sample was stable for several years. The closed hydrogen cover was stable and the oxygen back-bonded during the lowtemperature oxygen anneal. In recent studies on the combustion performance of silicon-based nanoenergetic composites [32], and the explosive composite of porous silicon and sodium perchlorate [20], the need to passivate the silicon surface with hydrogen was clearly demonstrated.

\section{Choice of Oxidizer}

Several types of oxidizers have been utilised in nanoexplosive devices. The most detailed investigation into the properties of a range of oxidizers was performed in 2004 [4]. It was found that the perchlorates were much more efficient for energetic explosions than the nitrates. Less efficient oxidizers can, however, also be sufficient for certain applications, because the energy yield of the reaction is quite high.

The main problems with perchlorates are that they contain crystal water and are hygroscopic. There are a number of non-hygroscopic perchlorates, like $\mathrm{KClO}_{4}, \mathrm{NH}_{4} \mathrm{ClO}_{4}$ and $\mathrm{RbClO}_{4}$, but they are not solvable in common solvents in reasonable amounts. The crystal water and the hygroscopic nature of the perchlorates are disadvantages in terms of long term stability, but it was reported that the presence of crystal water was necessary for stabilising the salt inside the pores [4]. Non-hygroscopic perchlorates with no crystal water (e.g. $\mathrm{NH}_{4} \mathrm{ClO}_{4}$ ) tend to creep out of the pores after evaporation of the solvents. Most of the oxidizers in use are available in a powder format, and the simplest technique to impregnate the pores of the porous silicon with an oxidizer is to fill the pores from a solution containing the oxidizer. Due to the organophilic surface nature of the porous silicon, water does not penetrate the pores, and another solvent has to be used [23]. Methanol and ethanol are good solvents, and acetone can also be used in some instances. For example, $\mathrm{KClO}_{4}$, an oxidizer used frequently in pyrotechnics, is not hygroscopic but its solubility in alcohol is very low. A problem to overcome is the fact that oxidizers solvable in organic liquids are always hygroscopic. Some of the oxidizers investigated are summarized in Table 3. As was reported [4, 23], sulphur has a rather low melting point, around $113^{\circ} \mathrm{C}$, below the ignition temperature of the $\mathrm{Si} / \mathrm{S}$ composite. Since molten sulphur can wet the porous silicon surface, the pores can actually be impregnated using melted sulphur.

Even though $\mathrm{KNO}_{3}$ in Table 3 is not soluble in methanol or ethanol, impregnation of pores was reported using a $10 \%$ aqueous solution of $\mathrm{KNO}_{3}$ and subsequent rotary drying [33]. The observation was made that explosive behaviour could only be observed for porous layer thicknesses thicker than $60 \mu \mathrm{m}$. A $0.2 \mathrm{M}$ solution of $\mathrm{Gd}\left(\mathrm{NO}_{3}\right)_{3} \cdot 6 \mathrm{H}_{2} \mathrm{O}$ in ethanol was used in an explosive device for emission spectroscopy experiments [1].

Aluminium nitrate as an oxidizer was implemented and a $0.2 \mathrm{M}$ solution in ethanol was used for pore impregnation [17]. The results indicated that aluminium nitrate was not as effective an explosive material as either gadolinium nitrate or sodium perchlorate. In the same study a high-explosive material RDX (cyclo-1,3,5-trimethylene-2,4,6trinitramine) was added $(0.2 \mathrm{M}$ in acetone) to the porous silicon pores. The results were not encouraging, possibly due to the fact that RDX is significantly deficient in oxidizing species. An unsuccessful attempt was also made to combine aluminium nitrate and RDX solution in an effort to supply an oxidizing species to the mixture. Furthermore, it should be mentioned that if RDX fills the pores, the length scale of RDX will be significantly smaller than the critical diameter for detonation. The poor performance may also be likely because the RDX is too small, and also has a poor thermal conductivity. Thus the RDX just cannot react fast and contribute to the reaction.

Another oxidizer that was loaded into the pores in liquid format was liquid fluorocarbon (PFPE) [19]. A small amount of the oil was placed onto the surface of the porous sample, and after 5 minutes in a $0.165 \mathrm{~atm}$ vacuum the mass of the samples indicated that the mixture ratio was $75 \%$ PFPE to $25 \%$ Si by mass in the pores. The samples could, however, not be ignited using hotwires, and the samples were finally ignited by holding a flame to the samples for about 10 to 20 seconds. The low ignition sensitivity of the PFPE is likely due to the chemical stability of the PFPE polymer chain.

In summary, the most popular oxidizers are calcium perchlorate and sodium perchlorate, also since they have shown the most promise in terms of their ability to stay inside the pores [34]. It was experimentally shown that the migration of the oxidizer may be dependent on the content of water molecules in the pores. Using anhydrous ethanol versus 
methanol to dissolve the salt minimizes the water content in the pores. Due to the larger concentration of water in the methanol, the drying process appears to be causing the dislocation of the salt as the water inside the porous network begins to evaporate. This process tends to push the salt crystals out of the pores [34].

Table 3. Properties of some common oxidizers. Reproduced with permission from [23]. (c) 2005 WILEY-VCH.

\begin{tabular}{|c|c|c|}
\hline Oxidizer & $\begin{array}{l}\begin{array}{l}\text { Solvent } \\
\text { (Solubility) }\end{array} \\
\end{array}$ & Remarks \\
\hline Perchlorates & & Most efficient, but if solvable also hygroscopic \\
\hline \multirow[t]{2}{*}{$\mathrm{Ca}\left(\mathrm{ClO}_{4}\right)_{2} \cdot 4 \mathrm{H}_{2} \mathrm{O}$} & $\operatorname{Me}(237 \mathrm{~g} / 100 \mathrm{~g})$ & Strongly hygroscopic, but very efficient \\
\hline & Et $(166 \mathrm{~g} / 100 \mathrm{~g})$ & \\
\hline \multirow[t]{2}{*}{$\mathrm{NH}_{4} \mathrm{ClO}_{4}$} & $\operatorname{Me}(6 g / 100 g)$ & Does not stay in pores; weaker reaction, lesser \\
\hline & $A c(>6 g / 100 g)$ & oxygen yield due to water production \\
\hline \multirow[t]{3}{*}{$\mathrm{LiClO}_{4} \cdot 3 \mathrm{H}_{2} \mathrm{O}$} & $\operatorname{Me}(182 \mathrm{~g} / 100 \mathrm{~g})$ & Does not stay in the pores, takes a while to \\
\hline & Et $(152 \mathrm{~g} / 100 \mathrm{~g})$ & come to the surface \\
\hline & Ac $(137 g / 100 g)$ & \\
\hline \multirow[t]{2}{*}{$\mathrm{NaClO}_{4} \cdot 1 \mathrm{H}_{2} \mathrm{O}$} & $\mathrm{Me}(\approx 181 \mathrm{~g} / 100 \mathrm{~g})$ & Less hygroscopic and stay inside the pores \\
\hline & Et $(<181 \mathrm{~g} / 100 \mathrm{~g})$ & \\
\hline \multirow[t]{3}{*}{$\mathrm{KClO}_{4}$} & $\operatorname{Me}(<1.7 \mathrm{~g} / 100 \mathrm{~g})$ & Not solvable in any common solvent \\
\hline & Et $(<1.7 \mathrm{~g} / 100 \mathrm{~g})$ & \\
\hline & Ac $(<1.7 \mathrm{~g} / 100 \mathrm{~g})$ & \\
\hline Nitrates & & $\begin{array}{l}\text { Less efficient than perchlorates, hygroscopicity } \\
\text { comparable }\end{array}$ \\
\hline \multirow[t]{2}{*}{$\mathrm{Ca}\left(\mathrm{NO}_{3}\right)_{2} \cdot 4 \mathrm{H}_{2} \mathrm{O}$} & $\mathrm{Me}(>54 \mathrm{~g} / 100 \mathrm{~g})$ & Strongly hygroscopic \\
\hline & Et $(54 \mathrm{~g} / 100 \mathrm{~g})$ & \\
\hline \multirow[t]{2}{*}{$\mathrm{NH}_{4} \mathrm{NO}_{3}$} & $\operatorname{Me}(17 g / 100 g)$ & Does not stay inside the pores \\
\hline & Et $(4 g / 100 g)$ & \\
\hline \multirow[t]{2}{*}{$\mathrm{KNO}_{3}$} & $\mathrm{Me}$ & Bad solubility, therefore no reaction \\
\hline & Et & \\
\hline \multicolumn{3}{|l|}{ Others } \\
\hline \multirow[t]{2}{*}{ Sulphur } & $\mathrm{CS}_{2}$ (good) & The only non-hygroscopic material, which \\
\hline & Melting & stays inside the pores. \\
\hline
\end{tabular}

\section{Impregnation of the Pores}

The simplest method to impregnate the pores is to fill the pores from a solution containing the oxidizer. Small alcohol molecules, for example methanol and ethanol, combine good solubility of the oxidizing salts (see Table 3) and organophilic behavior.

The pores can be filled by dropping oxidizer solution with a pipette or syringe directly on the porous silicon surface [12]. The solution is drawn inside the pores by capillary forces. In most cases only two drops of solution will be drawn into the pores. If more drops can be applied, the first two drops are allowed to visually dry before applying additional drops. A different approach was reported as well, where the porous layer is coated evenly with the oxidizer three consecutive times, while the sample remains wet, to ensure sufficient oxidizer impregnates the pores [26]. The sample is then dried in a humidity controlled box flooded with $\mathrm{N}_{2}$ gas, allowing the solvent to evaporate and the oxidizer to crystallize inside the pores [12]. The dropcasting can also preferably be performed inside a container under a constant $\mathrm{N}_{2}$ purge where relative humidity $<2 \%$ can be achieved to prevent hygroscopic oxidizers from absorbing moisture [21]. The impregnated sample is then allowed to dry for at least 20 minutes prior to use. The impregnation process can also be done with the assistance of ultrasonic waves [22].

Another method to fill the pores is to immerse the sample in an oxidizer/methanol solution [18]. Both the sample and solution can be placed under a rough vacuum at $0.165 \mathrm{~atm}$ for a prescribed filling time. For the samples with porosities of $55 \%$ the chosen filling time was approximately 15 minutes, and for samples with porosities greater than $70 \%$ the chosen filling time was 5 minutes. The samples were then dried at $38^{\circ} \mathrm{C}$ overnight [18]. An observation often seen after the pore impregnation drying procedure is that the samples appear to exude the oxidizer leaving a layer of white crystals on the porous silicon surface. This 
expulsion of oxidizer was especially observed for samples filled with $\mathrm{NaClO}_{4} \cdot 1 \mathrm{H}_{2} \mathrm{O}$, but not for samples loaded with $\mathrm{Ca}\left(\mathrm{ClO}_{4}\right)_{2} \cdot 4 \mathrm{H}_{2} \mathrm{O}[18,20]$. This thin residue of oxidizer on the surface can easily be removed with a moist cotton swab dipped in ethanol [18].

In the case of sulphur, an organophilic and nonpolar solvent, $\mathrm{CS}_{2}$, can be used. However, melted sulphur can also be used to fill the pores. Sulphur has a rather low melting point, below the ignition temperature of the silicon/sulphur composite, and wets the porous silicon surface well. The filling factors achieved with melted sulphur are comparable to the filling from the $\mathrm{CS}_{2}$ solution, but not sufficient to reach the stoichiometric ratio of $\mathrm{SiS}_{2}$ [23].

The effective filling factor of the pores can be defined as the ratio of pore volume filled by the oxidizer after impregnation, relative to the total pore volume. Using gravimetric techniques, the effective filling factor of the pores could be determined as a function of pore size $[15,35]$. The oxidizer solutions used to perform the experiment were: $1 \mathrm{~g}$ of $\mathrm{S}$ in $5 \mathrm{ml}$ of $\mathrm{CS}_{2}, 1 \mathrm{~g}$ of $\mathrm{NaClO}_{4} \cdot 1 \mathrm{H}_{2} \mathrm{O}$ in $5 \mathrm{ml}$ of methanol and $1 \mathrm{~g}$ of $\mathrm{Gd}\left(\mathrm{NO}_{3}\right)_{3} \cdot 6 \mathrm{H}_{2} \mathrm{O}$ in $5 \mathrm{ml}$ of ethanol. The results obtained are shown in Figure 2 where it is noticed that smaller pore sizes have smaller filling factors for all oxidizers, as could be expected. It is also noted that $\mathrm{NaClO}_{4} \cdot 1 \mathrm{H}_{2} \mathrm{O}$ has the highest filling factor approaching $75 \%$. The results are consistent with a previous report that the filling factors achieved were in the order of $50 \%$ for all oxidizers [23].

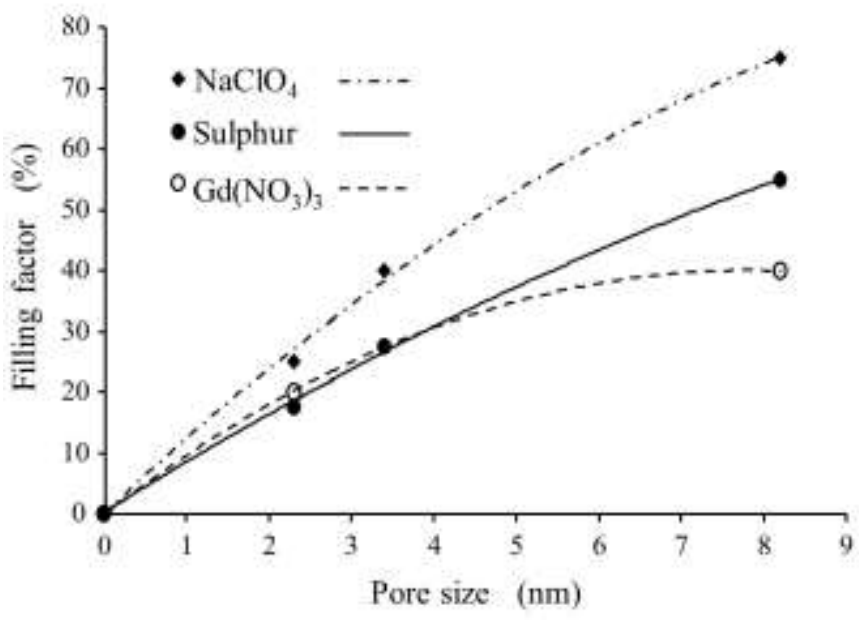

Figure 2. Filling factor as a function of pore size and type of oxidizer. Reproduced with permission from [15]. (C) 2007 Elsevier.

Since the samples are very sensitive after impregnation, no SEM studies regarding the distribution of the oxidizer within the pore structure have been undertaken. Capillary action draws the oxidizer, dissolved in the solvent, into the pores and during the drying process the solvent evaporates and leaves the solid state oxidizer in the pores. During the research into the filling factors that can be achieved [15], thinned porous silicon samples were prepared with the porous layer extending right through the wafer. The sample thicknesses used were 50 and $100 \mu \mathrm{m}$. Experimentally it was found that in the case of the $3.4 \mathrm{~nm}$ pore size, the oxidizer sodium perchlorate could penetrate right through the $50 \mu \mathrm{m}$ sample from the front to rear side (drop casting impregnation at front of wafer only) through capillary action, but in the case of the $100 \mu \mathrm{m}$ sample the capillary action could not transfer the oxidizer to the rear of the wafer. This means that the maximum depth of penetration is between 50 and $100 \mu \mathrm{m}$, and one expects the oxidizer concentration to decrease from the front side towards the rear of the sample. The samples are not homogenously filled, except near the surface from where drop casting was performed.

In general the pore size and porosity in relatively thick porous silicon layers $(\approx 20 \mu \mathrm{m})$ will vary as a function of distance from the front surface [36]. It is believed that this porosity and pore size gradient in the layer, with higher porosity and larger pore size near the surface, is related to the chemical dissolution of the porous material during porous formation since the top part of the porous layer has been exposed to the chemicals for a longer period of time. This adds to the fact that the oxidizer impregnation of the pores is not homogenous, with more oxidizer near the surface.

\section{Ignition of the Oxidizer}

The first porous silicon explosive prototypes were ignited by scratching the surface with a diamond scribe [1]. Subsequent developments showed that the oxidizers can be ignited thermally, electrically or optically. Thermal ignition was performed using a hot plate, and it was experienced that below a certain heating rate the oxidizer decomposes and does not explode, although no mention is made of the required heating rate $[4,23]$. Electrical ignition made use of a $\mathrm{Ni} / \mathrm{Cr}$ heating bridge element on a ceramic substrate. Optical ignition with a single pulse from a YAG laser could also initiate the explosive reaction. In Table 4 the empirical initiation temperatures for some common oxidizers are given.

Table 4. Measured initiation temperatures of some common oxidizers.

\begin{tabular}{lllll}
\hline Reference & $\mathrm{Ca}\left(\mathrm{ClO}_{4}\right)_{2}$ & $\mathrm{NaClO}_{4}$ & Sulphur & $\mathrm{Gd}\left(\mathrm{NO}_{3}\right)_{3}$ \\
\hline$[4]$ & $185-210^{\circ} \mathrm{C}$ & $308-337^{\circ} \mathrm{C}$ & $239-267^{\circ} \mathrm{C}$ & \\
{$[35]$} & & $313^{\circ} \mathrm{C}$ & $261^{\circ} \mathrm{C}$ & $243^{\circ} \mathrm{C}$ \\
{$[16]$} & & $320^{\circ} \mathrm{C}$ & &
\end{tabular}

[34] $225^{\circ} \mathrm{C}$

Electrical ignition utilises a hotwire or heating bridge element in close contact with the oxidizer. An aluminium thin film hotwire in close contact with a $3.5 \mathrm{~mm}$ diameter porous silicon/oxidizer composite was investigated [37]. The film had a thickness of $1 \mu \mathrm{m}$, and the best results were obtained for hotwire geometry of $150 \mu \mathrm{m} / 600 \mu \mathrm{m}$ width/length ratio. The time responses of the current flowing through the thin film fuse, as well as the optical signal from the nanoexplosion, are shown in Figure 3. The time delays in the figure are defined as: 
$t_{F}$ : Time that current flows through aluminium fuse;

$t_{D}$ : Delay time before oxidizer is ignited;

$t_{E}$ : Duration of the detected optical signal from the nano-explosion.

The aluminium hotwire had an electrical resistance of $0.2 \Omega$ and the drive current $I_{F}=20 \mathrm{~A}$ flowed for a period $t_{F}=10 \mu \mathrm{s}$ to fuse the element. This represents initiation energy of $0.8 \mathrm{~mJ}$ to ignite the nano explosion. The experimental results for three oxidizers are shown in Table 5. From this table it can be seen that it was possible to ignite a nano-explosive device using $\mathrm{NaClO}_{4}$ as oxidizer and an aluminium fuse within $100 \mu \mathrm{s}$ from the onset of the hotwire voltage, using less than $1 \mathrm{~mJ}$ of initiation energy.

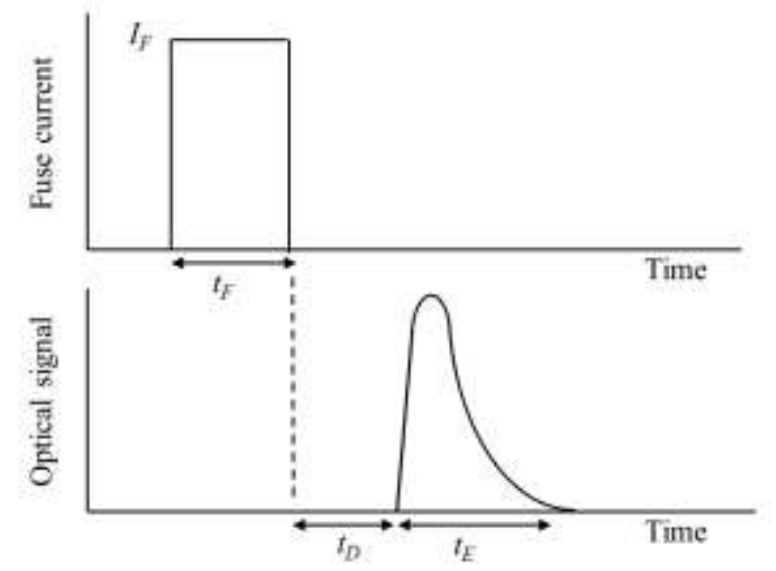

Figure 3. Time response of oxidizer ignition using aluminium hotwires. Reproduced with permission from [37]. () 2008 Elsevier.

Table 5. Time responses of aluminium thin film hotwires and the ignition of some porous silicon/oxidizer composites [37].

\begin{tabular}{llll}
\hline Period & $\mathrm{NaClO}_{4}$ & Sulphur & $\mathrm{Gd}\left(\mathrm{NO}_{3}\right)_{3}$ \\
\hline$t_{D}$ & $80 \mu \mathrm{s}$ & $550 \mu \mathrm{s}$ & $1000 \mu \mathrm{s}$ \\
$t_{E}$ & $5 \mathrm{~ms}$ & $45 \mathrm{~ms}$ & $20 \mathrm{~ms}$ \\
\hline
\end{tabular}

In the above experiment the aluminium hotwire was deposited on a second substrate, and then placed in close contact with the porous silicon sample impregnated with the oxidizer. The delays $t_{D}$ from the fusing of the aluminium hotwire to the ignition of the oxidizer will be a function of the thermal conductivities of the hotwire assembly, the porous silicon structures well as of the specific oxidizer. Better and more repeatable thermal characteristics will be achieved if the hotwire can be deposited directly onto the surface of the porous silicon sample filled with the oxidizer.

Hotwire finite element simulations were performed to design hotwires deposited directly on the porous silicon, making use of the much lower thermal conductance of the porous silicon, and thus ensuring more efficient hotwire initiation [34]. The first monolithically integrated initiator for efficient low-power electronic initiation was reported in 2009 [19]. Following the porous etch, the hotwire stack materials were deposited, and patterned using either shadow masking or photolithography, with the latter method giving tighter geometrical control and better reproducibility. The hotwire stack was $200 / 1000 / 3800 \AA \mathrm{Ti} / \mathrm{Pt} / \mathrm{Au}$ and had a typical width of $25 \mu \mathrm{m}$ and a length of $500 \mu \mathrm{m}$. Using these hotwires, a porous silicon device with $\mathrm{NaClO}_{4}$ as oxidizer could be ignited within $475 \mu \mathrm{s}$ with a current of $840 \mathrm{~mA}$ from a $2.8 \mathrm{~V}$ supply. The initiation energy needed was calculated as $0.83 \mathrm{~mJ}$, a value very similar to the aluminium thin film hotwire reported earlier [37]. Further optimisation of the hotwire stack led to dimensions of $15 \mu \mathrm{m} / 75 \mu \mathrm{m}$ and $15 \mu \mathrm{m} / 125 \mu \mathrm{m}$, and ignition times with a $5 \mathrm{~V}$ supply were $120 \mu \mathrm{s}$ and $88 \mu \mathrm{s}$ respectively, with peak currents less than $100 \mathrm{~mA}$ [26]. The electrical initiation energy was in the range of $0.1 \mathrm{~mJ}$. The use of $\mathrm{Cr}$ micro bridges as reliable hotwire heating elements was also demonstrated, and initiation energies varied from 0.15 to $0.29 \mathrm{~mJ}$ to ignite porous silicon devices with $\mathrm{NaClO}_{4}$ as oxidizer, with ignition delay times varying from 80 to $110 \mu$ s [38]. From the above studies it is evident that the reaction time of the oxidizer ignition process after the onset of the hotwire voltage is a strong function of the hotwire geometry. Furthermore, the delays $t_{D}$ tabulated in Table 5 were not experienced with the hotwire element deposited directly on the surface of the porous silicon/oxidizer device.

Optical ignition with a single pulse from a YAG laser could also initiate the explosive reaction [4], although the power density and pulse duration were not reported. Laser ignition using a $514 \mathrm{~nm}$ laser at $37.7 \mathrm{~mW}$ and a power density of $2.7 \mathrm{~kW} \mathrm{~cm}^{-2}$ at a stand-off distance of $23 \mathrm{~cm}$ was also reported [39]. In another laser initiation application a Q-switched $\mathrm{Nd}$ :YAG laser of $532 \mathrm{~nm}$ wavelength was used [40]. The laser had a $15 \mathrm{~ns}$ pulse duration and the igniting energy was $264 \mathrm{~mJ}$. No indication was given concerning the time response of the optical ignition processes.

A very interesting initiation technique combined optical and mechanical means [41]. Energy can be stored as residual stress in a deposited thin film. This novel actuator powered by residual thin film mechanical stress absorbed $25 \mathrm{~W} \mathrm{~cm}^{-2}$ of optical power from a $532 \mathrm{~nm}$ visible laser, heated, and released up to $22 \mathrm{~nJ}$ of mechanical energy, sufficient to release almost $10 \mathrm{~kJ} \mathrm{~g}^{-1}$ of chemical energy from the sodium perchlorate impregnated porous silicon. The irradiation level needed was nearly 80 times less than previous direct optical initiation via laser. Since the actuation process is the result of a thermal process, the time response is relatively slow. Irradiation with $25 \mathrm{~W} \mathrm{~cm}^{-2}$ of optical power resulted in an explosion within $30 \mathrm{~ms}$.

Another novel development combined carbon nanotubes and porous silicon. This nanostructured energetic material combined multi-walled carbon nanotubes, mixed with ferrocene, with porous silicon impregnated with sodium perchlorate [42]. It was demonstrated that the porous silicon can be exploded using the carbon nanotubes as photosensitive initiators using a camera flash. As the temperature of the 
carbon nanotubes is raised indirectly by the camera flash, which induces photo-acoustic vibrations, some of the carbon is oxidized releasing the metal nanoparticles into the surroundings and in the presence of oxygen the carbon will combust with a self-sustaining flame. The porous silicon explosion is ignited using the light induced multi-walled carbon nanotubes ignition.

\section{Characteristics of Porous Silicon Explosions}

The efficiency of the explosive reactions is defined by two parameters, namely the release of energy and the reaction rate [7]. Other characteristics of importance are the emission spectrum of the optical signal resulting from the explosion, the gas released during the reaction, as well as the sensitivity of the explosive device to mechanical shock and electrostatic discharge.

\subsection{Reaction of Oxygen with Hydrogenated Porous Silicon}

It is known that hydrogen is present in the chemical composition of porous silicon, especially in asprepared samples, as a result of the etching technology [43]. The investigation of the explosive properties of porous silicon shows the important role of bonded hydrogen in these processes.

The initial process of the porous silicon reaction with oxidizers depends on the important role of $\mathrm{Si}-\mathrm{H}$ bonds $[7,43]$. The fundamental explosion is the energy released under the interaction of oxygen molecules with dangling $\mathrm{Si}$ bonds acting as free radicals. The three principal steps in the porous silicon explosion are indicated in Figure 4. The explosion can be ignited, for example, by rupturing the surface $\mathrm{Si}-\mathrm{H}$ bonds and creating dangling bonds, see Figure $4(A)$. Hydrogen atoms covering porous silicon are the buffer between $\mathrm{Si}$ atoms and molecular oxygen, which prevents oxygen and silicon interaction. The instantaneous character of the reaction indicates that in the second stage, Figure $4(\mathrm{~B})$, hydrogen is removed from the surface via an exothermic reaction between oxygen and hydrogen, which forms water and/or $\mathrm{OH}$ radicals. The removal of hydrogen atoms from the surface and disruption of Si-Si bonds is followed by formation of new radicals. It initialises the next step of the reaction, when surface $\mathrm{Si}$ atoms interact directly with oxygen, and the oxidation of the silicon nanostructure is achieved; see Figure $4(\mathrm{C})$. This interaction of molecular oxygen with dangling bonds results in the creation of new interacting free radicals: silicon dangling bonds, atomic hydrogen and oxygen, $\mathrm{OH}$ groups and $\mathrm{SiOH}$ groups.
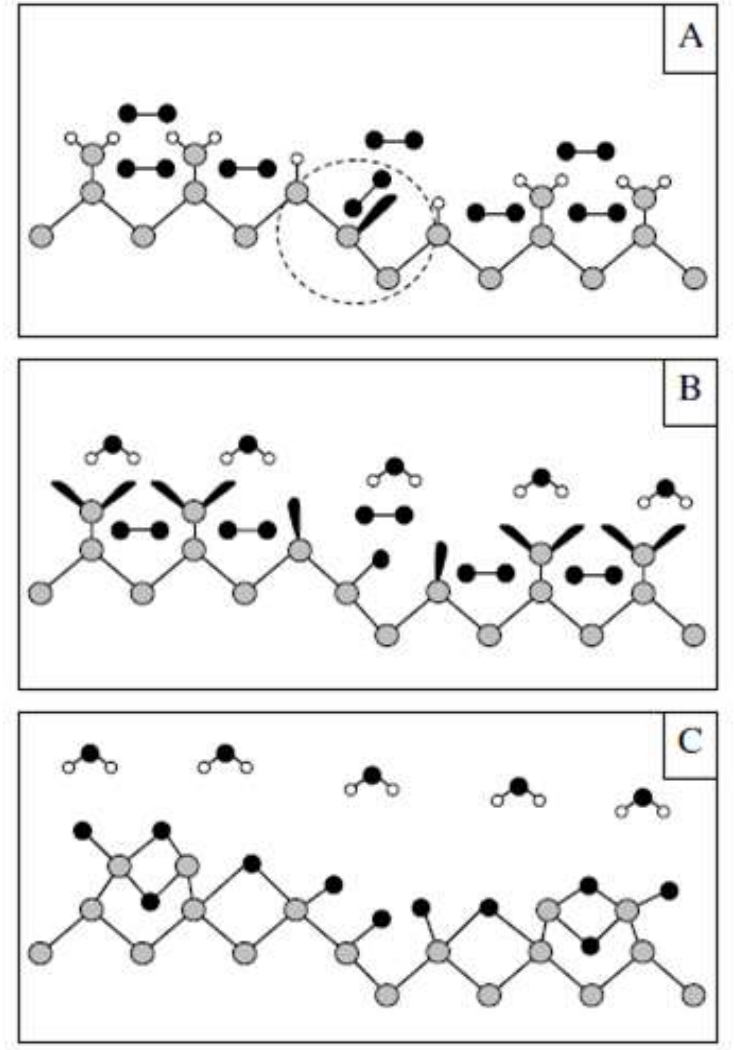

Figure 4. Two-dimensional sketch of the three principal steps ( $A, B$, and $C$ ) of the explosive reaction of oxygen with hydrogenated porous silicon. Black circles: oxygen atoms, gray circles: silicon atoms, open circles: hydrogen atoms. The Si dangling bonds are indicated by black lobes. The dashed circumference indicates the ignition site of the reaction. Reproduced with permission from [7]. (C) 2001 The American Physical Society.

Time-resolved emission during energetic reactions and infrared absorption analysis after explosions indicate the formation of $\mathrm{O}$ and $\mathrm{OH}$ radicals during the explosion. A detailed chemical mechanism for the formation of $\mathrm{O}$ and $\mathrm{OH}$ radicals based on QRRK (Quantum Rice-Ramsperger-Kassel) estimates were presented [16]. It is believed that production of $O$ atoms followed by the chemical reaction

$$
\mathrm{Si}_{n} \mathrm{H}_{2 n+2}+\mathrm{O}=\mathrm{SiH}_{3}+\mathrm{OH}
$$

provide chain branching, which is responsible for the low temperature explosive behaviour [16].

From the above analysis it seems that although hydrogen plays an important role in the chain reaction, it does not get liberated in the form of hydrogen gas $\mathrm{H}_{2}$, but rather reacts with the fuel and oxidizer to form $\mathrm{Si}-\mathrm{H}$ and $\mathrm{O}-\mathrm{H}$ radicals to further take part in the chain reaction. It was hypothesized that the majority of the gas generation released by the explosion was in the form of water vapor [26]. 


\subsection{Effect of Pore Size}

The explosive responses shown in Figure 5 are indicative of the relative energies released by three different oxidizers [15], with the sodium perchlorate explosion significantly more energetic than the oxidizers gadolinium nitrate and sulphur. The sulphur seems to be more of a gaseous type of explosion, with a characteristic "mushroom cloud". This observed sulphur explosive behaviour was subsequently theoretically interpreted and explained [29]. The sodium perchlorate oxidizer destroyed the sample in all cases and ejected silicon shrapnel in all directions. The gadolinium nitrate explosion ejected small porous silicon crystallite particles from the porous region in a vertical fashion, with the rest of the silicon sample intact.

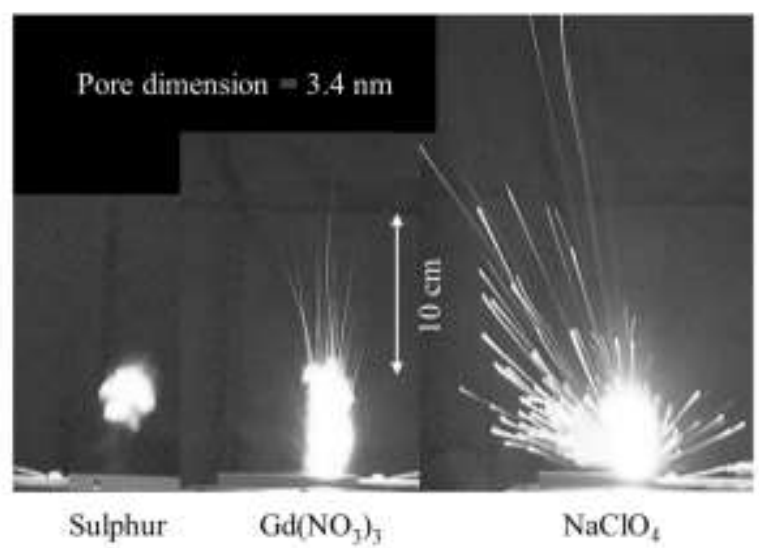

Figure 5. Optical emissions from different oxidizer nano-explosions. Reproduced with permission from [15]. @ 2007 Elsevier.

The effect of pore size on the explosive energy is illustrated in Figure 6 . The energy released by the oxidizer gadolinium nitrate with a pore size of $3.4 \mathrm{~nm}$ is significantly more than those devices with $2.3 \mathrm{~nm}$ and $8.2 \mathrm{~nm}$ pore sizes. Similar responses were observed for other oxidizers. An approximate Figure of Merit (FOM) was defined based on the sound of the explosion, physical damage done to the sample, the distance that particles were ejected from the sample and the time integral of the optical signal [15]. Using this FOM the relative strengths of explosions as a function of pore size for different oxidizers were estimated [35,37]. The FOM results are shown in Figure 7.

From Figure 7 it can be seen that a pore size in the region of 3 to $4 \mathrm{~nm}$ was optimal for devices using the oxidizers shown in the figure [37]. Another study concluded that a pore size of $11.8 \mathrm{~nm}$ was optimal for the oxidizer aluminium nitrate [17]. There is evidently an optimum pore size suited to specific explosive systems.

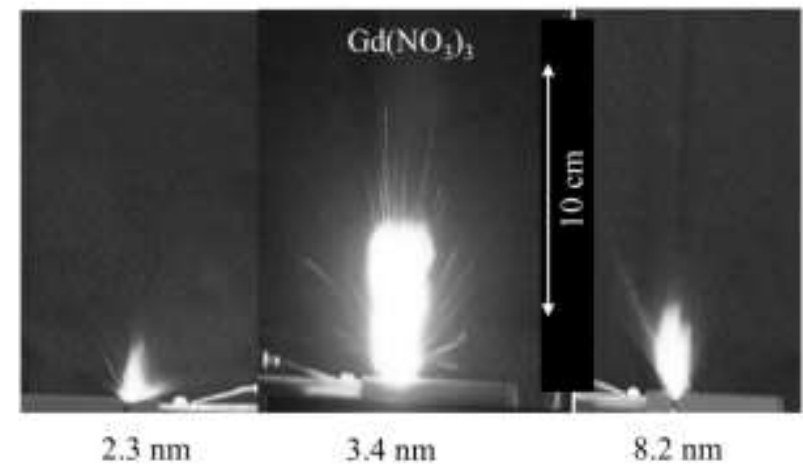

Porous silicon pore size

Figure 6. Optical emissions from different pore size nano-explosions using $\mathrm{Gd}\left(\mathrm{NO}_{3}\right)_{3}$ as oxidizer. Reproduced with permission from [37]. (C) 2008 Elsevier.

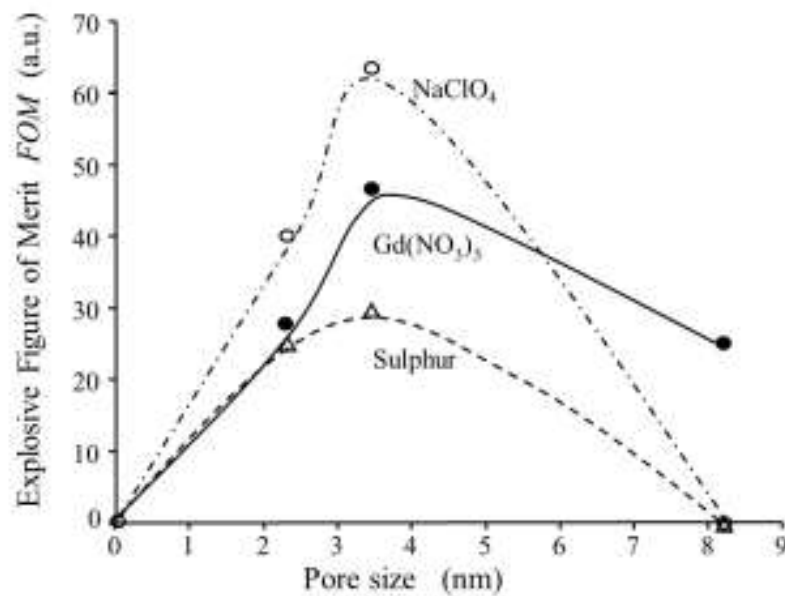

Figure 7. Explosive figure of merit (FOM) for three common oxidizers vs. pore size. The trend lines were added to guide the eye. Reproduced with permission from [37]. @ 2008 Elsevier.

\subsection{Theoretical Energy Yield}

In a recent study the impregnation process was investigated in order to achieve optimized pore filling by sodium perchlorate as oxidizer [24]. Thermochemical calculations were performed to estimate the maximum energy output for porous silicon with sodium perchlorate oxidizer in both its anhydrous and monohydrate forms. This study showed that there is an optimum oxidizer/fuel (O/F) mass ratio for maximum energy release, close to the stoichiometric $\mathrm{O} / \mathrm{F}$ mass ratio of the reactions, and any $\mathrm{O} / \mathrm{F}$ ratio more or less than this value results in less energy release. In Figure 8 is shown the theoretical energy outputs versus $\mathrm{O} / \mathrm{F}$ mass ratio for porous silicon impregnated with anhydrous and monohydrate sodium perchlorate. The maximum energy output for both mixtures is $\approx 10 \mathrm{~kJ} \mathrm{~g}^{-1}$, more than double that of TNT. The maximum energy outputs are achieved at a mass ratio $\mathrm{O} / \mathrm{F} \approx 2$. The decrease in energy output for larger $\mathrm{O} / \mathrm{F}$ ratios was also observed earlier [21]. It was postulated that excess amounts of $\mathrm{NaClO}_{4}$ will yield an 
overoxidized sample that will add extra thermal mass to the system that is not necessary for combustion and slows the reaction [21].

It is of interest to determine the oxidizer to fuel $(\mathrm{O} / \mathrm{F})$ molar and mass ratios for the devices used to generate the results shown in Figure 7 , by taking the filling factors of Figure 2 into account. The porous silicon structures in Figure 7 were designed to all have the same porosity of $70 \%$. The experimental values shown in Table 6 were calculated [37].

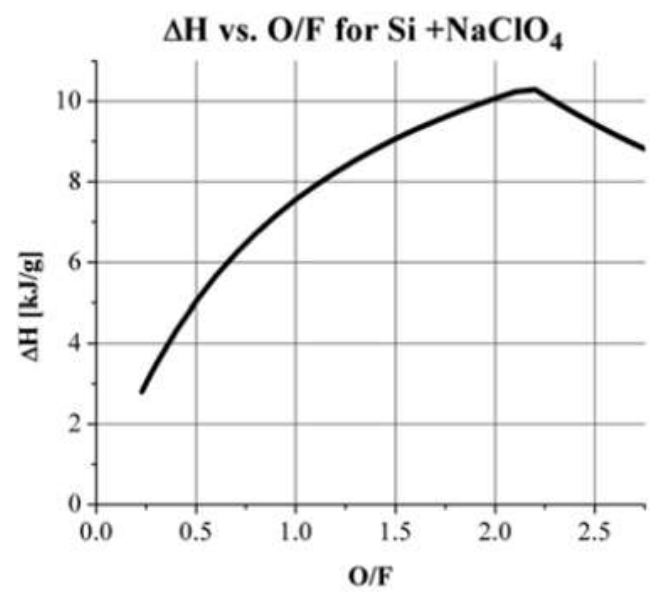

The impregnation filling factor was used to calculate the volume filled by the oxidizer. Using the density of silicon $\left(2.33 \mathrm{~g} \mathrm{~cm}^{-3}\right)$ and the density of monohydrate sodium perchlorate $\left(2.02 \mathrm{~g} \mathrm{~cm}^{-3}\right)$, as well as the molecular masses of 28.09 for silicon and 140.44 for monohydrate sodium perchlorate, the mass and molar $\mathrm{O} / \mathrm{F}$ ratios could be determined.

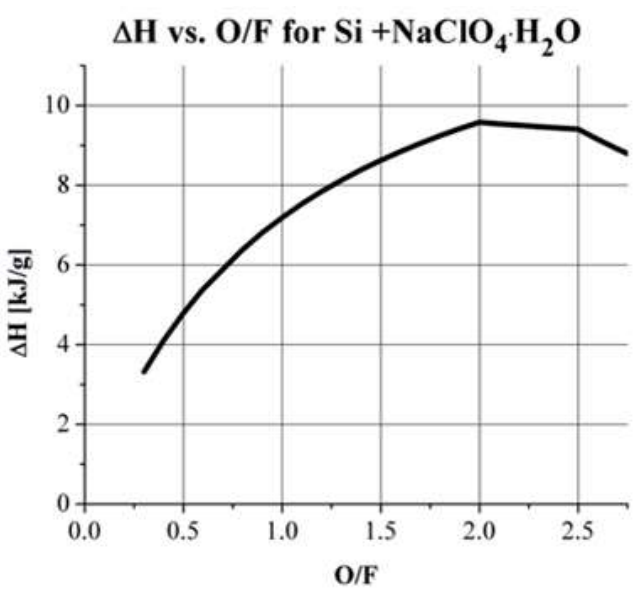

Figure 8. Theoretical thermochemical calculations of the energy output versus O/F mass ratio for porous silicon and sodium perchlorate. Left - anhydrous, and right - monohydrate. Reproduced with permission from [24]. (C) 2012 Begell House, Inc.

Table 6. The effect of pore size on monohydrate sodium perchlorate energy output with porosity $=70 \%$

\begin{tabular}{llllllll}
\hline $\begin{array}{l}\text { Pore } \\
\text { size }\end{array}$ & $\begin{array}{l}\text { Porous } \\
\text { volume }\end{array}$ & $\begin{array}{l}\text { Volume of } \\
\text { pores }\end{array}$ & $\begin{array}{l}\text { Volume } \\
\text { of Si }\end{array}$ & $\begin{array}{l}\text { Impregnation } \\
\text { fill factor }\end{array}$ & $\begin{array}{l}\text { Volume } \\
\text { of oxidizer }\end{array}$ & $\begin{array}{l}\text { O/F } \\
\text { molar ratio }\end{array}$ & $\begin{array}{l}\text { O/F } \\
\text { mass ratio }\end{array}$ \\
\hline $8.2 \mathrm{~nm}$ & $0.76 \mathrm{~mm}^{3}$ & $0.53 \mathrm{~mm}^{3}$ & $0.23 \mathrm{~mm}^{3}$ & $75 \%$ & $0.40 \mathrm{~mm}^{3}$ & 0.30 & 1.52 \\
$3.4 \mathrm{~nm}$ & $1.12 \mathrm{~mm}^{3}$ & $0.78 \mathrm{~mm}^{3}$ & $0.34 \mathrm{~mm}^{3}$ & $40 \%$ & $0.31 \mathrm{~mm}^{3}$ & 0.16 & 0.81 \\
$2.3 \mathrm{~nm}$ & $1.02 \mathrm{~mm}^{3}$ & $0.71 \mathrm{~mm}^{3}$ & $0.31 \mathrm{~mm}^{3}$ & $25 \%$ & $0.18 \mathrm{~mm}^{3}$ & 0.10 & 0.51 \\
\hline
\end{tabular}

It should be noted that the O/F molar ratios at $70 \%$ porosity calculated in Table 6 is almost identical to the experimental molar ratios reported previously for a comparable porosity of $68 \%$ [20]. In terms of the equivalence ratio (ratio of actual $\mathrm{F} / \mathrm{O}$ to stoichiometric $\mathrm{F} / \mathrm{O}$ ) the 0.1 to $0.3 \mathrm{O} / \mathrm{F}$ molar ratios translate to equivalence ratios of 5.0 and 1.66 respectively, which means that all of the samples are "fuel rich" [32].

To more accurately estimate the energy yield of the explosion, the binding energies of the $\mathrm{Si}-\mathrm{H}$, Si$\mathrm{Si}, \mathrm{O}-\mathrm{O}$ and $\mathrm{Si}-\mathrm{O}$ bonds, as well as the energy of water formation, were taken into account [7]. If only the surface silicon atoms were supposed to be converted into $\mathrm{SiO}_{2}$, and assuming that all hydrogen atoms were removed from the surface and interact with oxygen, the energy yield of porous silicon was estimated to be $12 \mathrm{~kJ} \mathrm{~g}^{-1}$. The typical density of the porous layer was assumed to be $1 \mathrm{~g} \mathrm{~cm}^{-3}$ in this estimation. If a complete oxidation of all silicon nanocrystals was achieved, the energy yield was estimated as $28 \mathrm{~kJ} \mathrm{~g}^{-1}$ [7]. The first solid state porous silicon explosive device enthalpy of reaction for the gadolinium nitrate oxidizer was estimated to be approximately $4.18 \mathrm{~kJ} \mathrm{~g}^{-1}$ [1].

\subsection{Experimental Energy Yield}

One of the first experimentally determined energy yields of porous silicon explosive devices was measured using a calorimetric bomb-test for porous silicon filled with calcium perchlorate as oxidizer $[4,23]$. The energy yield was measured as $7.3 \mathrm{~kJ} \mathrm{~g}^{-1}$ and compared well with the most powerful explosions known at that stage; all with energy yields less than $8 \mathrm{~kJ} \mathrm{~g}^{-1}$.

The influence of pore size and oxidizing agent on the energetic properties of porous silicon were determined experimentally using differential scanning calorimetry (DSC) techniques [17]. The highest energy output was measured for the oxidizer sodium perchlorate, almost $9 \mathrm{~kJ} \mathrm{~g}^{-1}$, which compared well with the theoretical predicted energy yield of $10.35 \mathrm{~kJ} \mathrm{~g}^{-1}$. The extent of the $\mathrm{NaClO}_{4}$ reaction was observed with bomb calorimetry in $\mathrm{N}_{2}$ and $\mathrm{O}_{2}$ atmospheres. Without the supplementary $\mathrm{O}_{2}$ environment, the heat of reaction was measured to be $9.9 \pm 1.8 \mathrm{~kJ} \mathrm{~g}^{-1}$, but with supplementary $\mathrm{O}_{2}$ the reaction yielded $27.3 \pm 3.2 \mathrm{~kJ} \mathrm{~g}^{-1}$ and approached the theoretical value of $33.0 \mathrm{~kJ} \mathrm{~g}^{-1}$ for complete Si oxidation [20]. 


\subsection{Reaction Gas Generation}

The ability to tune the energy release rate, as well as the gas generated during the explosion, has been demonstrated [26]. The proposed reaction of the porous silicon/sodium perchlorate system is

$$
\begin{aligned}
& n \mathrm{SiH}_{2}+(1-\mathrm{n}) \mathrm{Si}+(0.5+0.25 \mathrm{n}) \mathrm{NaClO}_{4} \rightarrow \\
& \mathrm{SiO}_{2}+\mathrm{NaCl}+\mathrm{n} \mathrm{H}_{2} \mathrm{O}+\text { heat }
\end{aligned}
$$

where the $\mathrm{SiH}_{2}$ arises from the hydrogen surface termination of the pore surface. The coefficient $n$ represents the ratio of silicon atoms on the surface to total silicon atoms in the porous silicon volume [44]. In some samples being studied, about $38 \%$ of the silicon atoms are estimated to be on the surface $(n=0.38)$. This corresponds to a ratio of hydrogen to silicon of up to 0.76 [44].

It was hypothesized that the majority of the gas generation was the formation of water vapor [26]. A calorimeter bomb chamber was used to conduct pressure measurements to determine the amount of gas generated by the $\mathrm{NaClO}_{4}$ reaction [44]. Using the ideal gas law, the pressure increase in the chamber was shown to correspond to $5.6 \times 10^{-4}$ moles of gas produced by the reaction. Taking the active mass into account, the gas generation per gram of active mass was $0.0189 \mathrm{~mol} \mathrm{~g}^{-1}$. This is sufficient for use in some propellant applications. For comparison, black powder produces $0.0125 \mathrm{~mol} \mathrm{~g}^{-1}$ and the best modern propellants produce in the order of $0.045 \mathrm{~mol} \mathrm{~g}^{-1}$ [44]. It was postulated that if all of the hydrogen in the reaction is oxidized to vapor phase $\mathrm{H}_{2} \mathrm{O}$ during the reaction, this would account for $0.0135 \mathrm{~mol} \mathrm{~g}^{-1}$, or over $70 \%$ of the measured gas generation. The remainder of the gas may come from water vapor from hydrated sodium perchlorate or from dissociation of excess sodium perchlorate into $\mathrm{Na}, \mathrm{Cl}_{2}$ and $\mathrm{O}_{2}$ gases.

By changing the quantity of hydrogen at the surface via thermal annealing of the freshly etched porous silicon at low temperatures, the amount of gas generated could be tuned. It was demonstrated that low temperature annealing in an oxygen atmosphere had a dramatic effect on the quantity of gas generated in the $\mathrm{NaClO}_{4}$ reaction, with almost no effect on the net energy output [26]. The gas generation per gram of active mass was $0.0129 \mathrm{~mol} \mathrm{~g}^{-1}$ for devices not annealed at low temperatures. When annealed at $250^{\circ} \mathrm{C}$ for $1 \mathrm{~min}$ in an oxygen environment the gas generation was only $0.004 \mathrm{~mol} \mathrm{~g}^{-1}$, a factor three smaller. This means that the removal of hydrogen from the surface of the porous silicon when low temperature annealing takes place in oxygen will decrease the amount of gas generation without influencing the energy released.

The temperature of the flame and the amount of gas generated during the nano explosion were also investigated theoretically. Chemical equilibrium calculations were performed using the equilibrium code, Cheetah 4.0, developed by Lawrence Livermore National Laboratory [45]. Calculations for the various oxidizers were performed by varying the composition of silicon vs. oxidizer. The equilibrium calculations indicate the nominal maximum flame temperature for most porous silicon oxidizer systems is about $3000 \mathrm{~K}$, with the oxidizer sulphur an exception where the flame temperature is only $1600 \mathrm{~K}$. The simulated maximum gas production of the porous silicon explosives ranged from $650 \mathrm{~cm}^{3} \mathrm{~g}^{-1}$ of reactant for sulphur to as high as $4800 \mathrm{~cm}^{3} \mathrm{~g}^{-1}$ of reactant for $\mathrm{NaClO}_{4}$.

\subsection{Propagation Speed}

Initially quite large values of propagation speeds of the detonation waves parallel to the surface were measured, using laser reflectivity techniques $[4,23]$. Propagation velocities in excess of $2000 \mathrm{~m} \mathrm{~s}^{-1}$ were measured using this technique. This was followed by high speed video imaging to measure the propagation velocity [26]. In this case an average velocity of about $1590 \mathrm{~m} \mathrm{~s}^{-1}$, was observed, with peak velocities in excess of $5000 \mathrm{~m} \mathrm{~s}^{-1}$, higher than the speed of sound in the material. It was, however, reported that these high velocities were measured during only one or two frames of the high speed videos, where the reaction front "jumps" $2 \mathrm{~cm}$ between frames in the 250000 frames per second video. This was the first report of erratic "jumps" in the reaction front movement using high speed video techniques that may lead to erroneous measurements [26]. Especially in the case of laser reflectivity techniques the "jump" of the reaction front may lead to too high values of velocity being measured. It was observed that the reaction appeared to move faster underneath the porous network, closest to the silicon substrate.

Another technique to determine the propagation velocity made use of a microfabricated diagnostic device with multiple integrated gold wire resistors spaced $5 \mathrm{~mm}$ apart to measure the wave velocity travelling along the length of the device. A deviation in the applied voltage across a resistor measured with an oscilloscope indicated the time at which the flame front of the reaction passed that point [21]. A high speed video camera was also used in assessing the speed measurement, which resulted in propagation velocities in excess of $3000 \mathrm{~m} \mathrm{~s}^{-1}$. No mention is made of "jumps" in the wave front from the video analysis, although the propagation velocities as measured are described as "dramatically faster than previously observed".

The results achieved above showed that the measurement of the propagation velocity is not straight forward and especially with laser reflection techniques the values measured may be in error. The high speed video analyses showed that there may be an erratic movement of the wave front that complicates the interpretation of the results.

Even though the absolute values of velocities measured may be in doubt, certain trends were identified. The propagation measurements indicated that the lower porosity samples exhibit faster propagation speeds [26]. The increased reaction velocity of the lower porosity samples is attributed to an increased speed of sound in the lower porosity porous silicon relative to the higher porosity 
counterpart [46]. An interesting development recently demonstrated that the propagation velocity can actually be controlled by structural modifications, for example manufacturing pillars of porous silicon on the surface [47]. The propagation speed for porous silicon with $\mathrm{Mg}\left(\mathrm{ClO}_{4}\right)_{2}$ as oxidizer could be varied from 1 to $500 \mathrm{~m} \mathrm{~s}^{-1}$, depending on the structural surface profiling used.

Eventually, in a very detailed and systematic study of nanoenergetic films consisting of nanostructured porous silicon impregnated with sodium perchlorate, the explosive properties of these films were investigated as a function of thickness, porosity, and confinement [48]. The sample burning rates were investigated using fiber-optic velocity probes, showing that the flame front velocities were very sensitive to the sample structural characteristics. In the confined samples, the reaction velocity peaked at a porosity of approximately $70 \%$, but dropped sharply above this point. It is, however, more interesting to plot the reaction velocity as a function of pore size from data extracted from the study report [48]. This relationship is shown in Figure 9. The correlation between the data shown in Figure 7 and Figure 9 is quite extraordinary, since two very different techniques were used to evaluate the energy released by the explosions, one very subjective using a Figure of Merit, and the other very much scientific and methodical measuring reaction velocity. A maximum reaction velocity will be achieved for a pore size of approximately $4 \mathrm{~nm}$ in both cases.

It was also shown that the reaction velocity increased with thicker porous layers, as was reported earlier, reaching a plateau for layers thicker than $30 \mu \mathrm{m}$. This is an important aspect to keep in mind when designing and manufacturing porous silicon explosive devices. Again, using data extracted from the previously mentioned study [48], the confined reaction velocity as a function of porous layer thickness can be plotted, as shown in Figure 10.

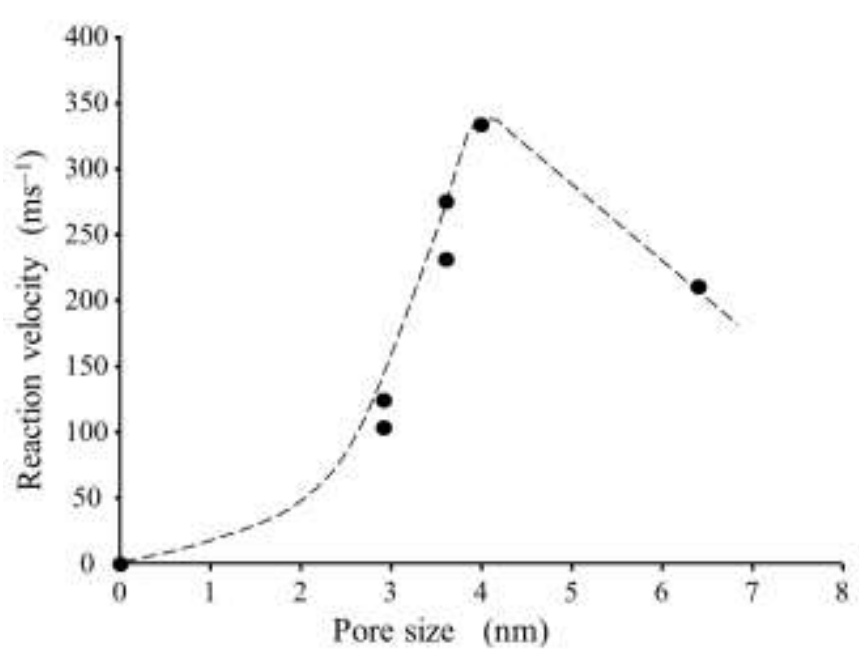

Figure 9. Reaction velocity as a function of pore size [48]. The dashed line is added to guide the eye.

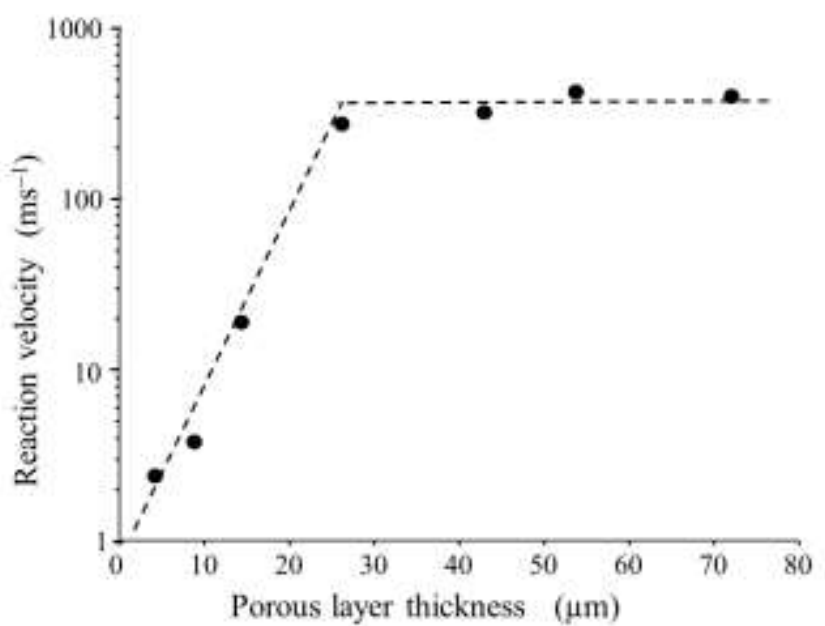

Figure 10. Reaction velocity as a function of porous layer thickness for confined samples [48].

From Figure 10 it is obvious that for porous silicon layers thicker than $30 \mu \mathrm{m}$ the reaction velocity reaches a maximum value of about $400 \mathrm{~m} \mathrm{~s}^{-1}$. In thin films, reaction products could diffuse out of the porous surface and not contribute to the advancement of the burning reaction. In thicker samples the reaction products would be trapped by the material above and be confined within the porous layer, unable to diffuse out of the surface easily, but would instead diffuse forwards into unburned material, thereby increasing the burning rate. The burning rate will eventually reach a maximum value when layers are thicker than $30 \mu \mathrm{m}$. The confinement effect was dramatically demonstrated by the shape of the wave front as a function of porous layer thickness [48]. For samples of less than $25 \mu \mathrm{m}$ thickness, the burning rate at the edge of the etched porous region increased and accelerated past the reaction front in the centre of the sample, such that the steady-state reaction front had the appearance of an inverted $\mathrm{V}$ as shown in Figure 11(a).

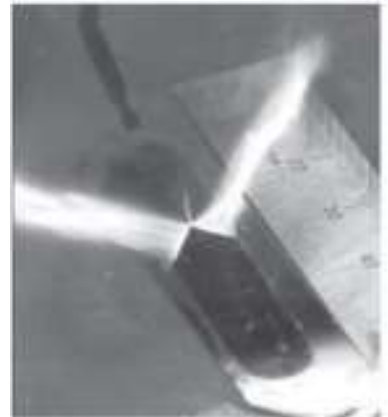

a)

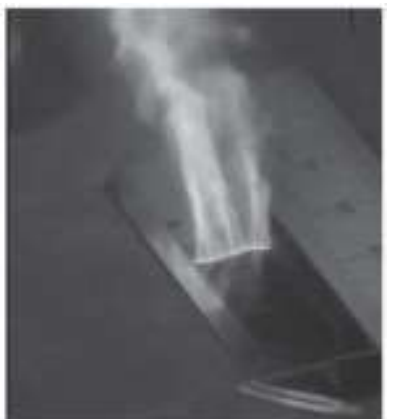

b)
Figure 11. a) Porous silicon sample of $24.9 \mu \mathrm{m}$ thickness displaying inverted $\mathrm{V}$ steady-state reaction front. Flame is proceeding toward the camera from the spark electrode at the top of the sample. b) Porous silicon sample of $49.9 \mu \mathrm{m}$ thickness displaying straight steady-state reaction front, advancing toward the camera. Reproduced with permission from [48]. () 2011 Wiley-VCH. 
The material at the edge experienced some confinement in the plane of the porous layer as a result of being near the porous silicon/unetched silicon interface. As can be seen in Figure 11(b), when the layer thickness is close to $50 \mu \mathrm{m}$, the confinement effect is almost uniform throughout the porous layer with the reaction front proceeding in an almost straight line across the width of the sample.

These reaction velocities are significantly lower than the velocities reported earlier, almost a factor ten slower. It is postulated that in velocity measurements based on laser reflectance on small samples, minor inaccuracies of the position of the laser spots may lead to a significantly large difference in the measured velocity [48]. High speed video analysis, however, showed a phenomenon that may explain the large variance seen in the quantitative velocity measurements. High speed video showed that the reaction front skipped ahead erratically and formed jets of flame emanating vertically out of the surface, several millimetres ahead of the main reaction front, similar to the observation reported earlier [26]. This effect is illustrated in Figure 12. It is possible that, due to the brittle nature of porous silicon, as well as the pressure generated within the surface, delamination of parts the porous layer from the bulk silicon can occur. This would provide for a fissure along which the highpressure flame and gas can jet under before finding another weakness and breaking out to the free surface [48].

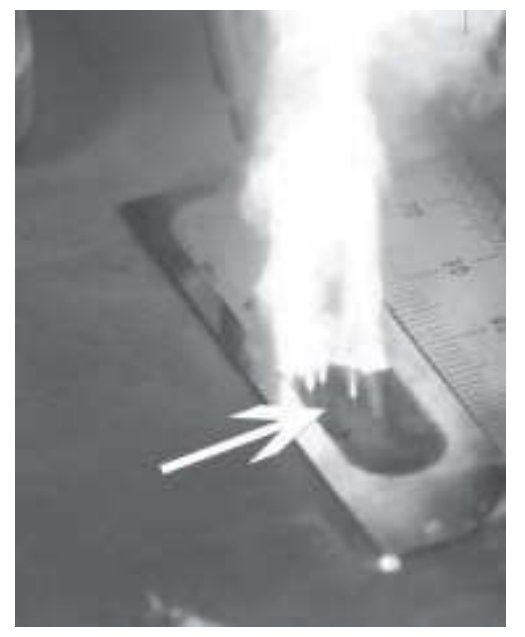

Figure 12. A porous silicon sample depicting flame breakthrough ahead of main reaction front. Reproduced with permission from [48]. (c) 2011 Wiley$\mathrm{VCH}$.

\subsection{Emission Spectrum}

The emission spectra from gadolinium nitrate loaded porous silicon explosive devices are of interest for use in atomic emission spectroscopy [1]. A typical emission spectrum is shown in Figure 13.

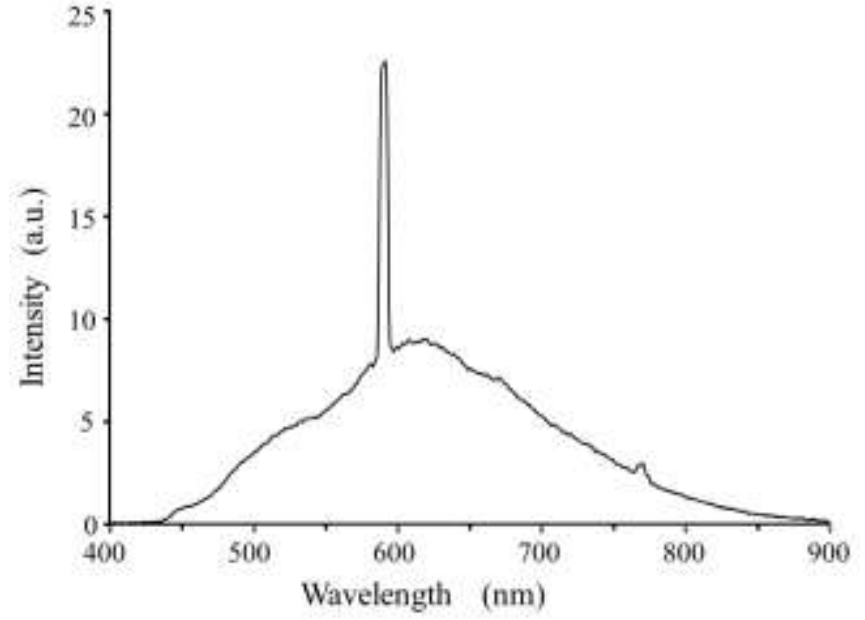

Figure 13. Spectrum of light emitted from porous silicon sample impregnated with $\mathrm{Gd}\left(\mathrm{NO}_{3}\right)_{3}$ as oxidizer.

Gadolinium nitrate does not have any significant atomic emission lines in the range 400$900 \mathrm{~nm}$. The sharp peak at $589 \mathrm{~nm}$ is due to sodium impurities from atmospheric contaminants. Similar wideband results were reported with the maximum emission intensity in the range of $680 \mathrm{~nm}$ for sodium perchlorate and aluminium nitrate [17]. A more detailed spectrum of calcium perchlorate emission also exhibited a wide band emission, but with a number of sharp plasma lines $[4,23]$. The maximum intensity of emission occurred at a wavelength of about $810 \mathrm{~nm}$, ignoring the spectral lines. It was postulated that the sharp spectral lines was an indication that the system was not in thermodynamic equilibrium, and the plasma lines belong to states of the mixture having different ionization levels.

\subsection{Explosive Device Mechanical and Electrostatic Sensitivity}

A series of tests were performed to quantify the sensitivity of energetic nanoporous silicon filled with sodium perchlorate to mechanical shock [34]. Beginning with half-sine shocks of $53 \mathrm{~g}$ for $10 \mathrm{~ms}$, and increasing the shocks up to $5131 \mathrm{~g}$ with duration of $0.2 \mathrm{~ms}$, no spontaneous ignitions could be initiated, indicating a low sensitivity to shock. Initiation via friction has been demonstrated with frictional forces ranging from $1.5 \mathrm{~N}$ down to $0.5 \mathrm{~N}$. The force was generated by moving a calibrated weight across the top of the oxidized porous silicon to scratch the surface. This induced stress causes the fuel and oxidizer to interact, such that an exothermic reaction is achieved [39].

Electrostatic discharge (ESD) sensitivity tests were carried out on porous silicon explosive devices manufactured using micron sized silicon powders and forming a network of porous silicon (4-5 nm nanocrystals) on the particle surface through chemical etching [30]. $\mathrm{NaClO}_{4}$ was used as oxidizer and the ESD testing was done according to military standards where the sample is subjected to 20 consecutive discharges at a particular energy level. The material was tested both as a powder and as a thin film. The 
discharge energy was increased up to $25 \mathrm{~mJ}$ with no ignitions. These tests suggested that the ESD sensitivity of porous silicon filled with sodium perchlorate was much lower than nanothermite systems based on aluminium.

\section{Applications of Porous Silicon Explosive Devices}

The still emerging technology of porous silicon explosives may find a number of applications [49]. The first application to be considered was that of using gadolinium nitrate porous silicon devices to not only act as the excitation source, but also as the matrix for the analyte, in atomic emission spectroscopy analysis [1].

An airbag initiator for the automotive industry was also developed where the porous silicon layer impregnated with an oxidizer was placed in direct thermal contact with a heating bridge, allowing the initiation of the standard booster charge of an industrial airbag [4, 23]. Fully integrated electronic detonators in the mining industry were the aim of a research program to develop porous silicon nano-explosive devices to be used as a primer for secondary explosives [35]. It is believed that reliable fully integrated igniters can be mass-produced using nanoporous silicon technology.

Nano-explosive devices can also be used in self-destructive silicon chips and in integrated circuit technology to divide silicon wafers into chips [33], or as a source of energy for silicon micro actuators [27]. It has also been proposed originally that there may be applications in the field of MEMS, where nanoexplosive devices can be used to propel miniature mechanical devices, for example mini rockets [11]. The first integration of nano-explosive porous silicon devices with a MEMS sensor has been demonstrated recently, as well as the first measurements of thrust generation using nanoporous energetic silicon [19]. This was followed by the first report of nano-explosive devices propelling miniature mechanical devices in 2012, in this case microrobots [50], realizing the prediction made a decade earlier in the popular engineering press [11].

\section{Conclusions}

The decade since the accidental discovery of the explosive properties of porous silicon in 2002 has been documented. The most important technological issues to design and manufacture porous silicon nano explosive devices were investigated and the optimization of the explosive properties was discussed.

The oxidizer sodium perchlorate was identified as the most energetic material, and the best porous silicon technological parameters to accommodate this oxidizer are porosities in the range 65 to $75 \%$, a pore size 2 to $5 \mathrm{~nm}$ and a porous layer thickness of about $50 \mu \mathrm{m}$. The porous silicon anodization can be performed with a current density of 20 to $70 \mathrm{~mA} \mathrm{~cm}^{-2}$ using p-type material in a 1:1 HF (49\%):ethanol electrolyte. Drying of the samples after the porous silicon formation can be achieved by rinsing the samples with ethanol or methanol, followed by the drying agent hexane or pentane, and also drying it subsequently under a gentle stream of nitrogen. To achieve long-term stability, the porous silicon surfaces should be stabilized by thermal annealing of the porous silicon sample in an oxygen atmosphere at $200-250^{\circ} \mathrm{C}$ after anodization. The pores can be impregnated by filling the pores using a pipette from a solution containing the oxidizer and ethanol or methanol. A typical solution will be dropcasting a $3.2 \mathrm{M}$ solution of $\mathrm{NaClO}_{4}$ in methanol or ethanol while inside a desiccator box under a constant $\mathrm{N}_{2}$ purge to maintain relative humidity $<2 \%$ and to prevent the highly hygroscopic $\mathrm{NaClO}_{4}$ from absorbing moisture. Using a hotwire heating element, the explosive can be initiated within $100 \mu \mathrm{s}$ using less than $0.1 \mathrm{~mJ}$ of electrical energy. Optical initiation via a laser pulse is also possible. The energy released during the nano explosion is in the region of $10 \mathrm{~kJ} \mathrm{~g}^{-1}$. A combustion propagation velocity of the energetic composite averaging approximately $400 \mathrm{~m} \mathrm{~s}^{-1}$ can be reached. There is, however, still some uncertainty about the accuracy of the methodologies used in determining the propagation velocities. The experimental determination of the propagation velocity is still an area of porous silicon explosive characterization that needs development.

A number of potential applications were identified for this new technology. Since the discovery of the first solid state porous silicon explosive device in 2002, significant progress has been made to gain further insights into this emerging technology and to develop reliable nano explosive devices.

\section{References}

[1] F. V. Mikulec, J. D. Kirtland, M. J. Sailor, Explosive Nanocrystalline Porous Silicon and Its Use in Atomic Emission Spectroscopy, Adv. Mater. 2002, 14, 38-41.

[2] C. Rossi, K. Zhang, D. Estève, P. Alphonse, P. Tailhades, C. Vahlas, Nanoenergetic Materials for MEMS: A Review, J. Microelectromech. Syst. 2007, 16(4), 919-931.

[3] Y-C. Liao, A. M. Nienow, J. T. Roberts, Surface Chemistry of Aerosolized Nanoparticles: Thermal Oxidation of Silicon, J. Phys. Chem. B 2006, 110, 6190-6197.

[4] D. Clement, J. Diener, D. Kovalev, Explosive Porous Silicon - From Laboratory Accident to Industrial Application, 35th Int. Conf. of ICT Energetic Materials - Structure and Properties, Karlsruhe, Germany, June 29-July 2, 2004, 5-15-11. 
[5] P. McCord, S.-L. Yau, A. J. Bard,

Chemiluminescence of Anodized and Etched

Silicon: Evidence for a Luminescent Siloxene-Like Layer on Porous Silicon, Science 1992, 257, 6869.

[6] P. D. Milewski, D. J. Lichtenwalner, P. Mehta, A. I. Kingon, D. Zhang, R. M. Kolbas, Light Emission from Crystalline Silicon and Amorphous Silicon Oxide $\left(\mathrm{SiO}_{\mathrm{x}}\right)$ Nanoparticles, J. Electron. Mater. 1994, 23(1), 57-62.

[7] D. Kovalev, V. Y. Timoshenko, N. Künzner, E. Gross, F. Koch, Strong Explosive Interaction of Hydrogenated Porous Silicon with Oxygen at Cryogenic Temperatures, Phys. Rev. Lett. 2001, 87(6), 068301(1-4).

[8] A. Grosman, C. Ortega, Chemical Composition of 'Fresh' Porous Silicon, in: Properties of Porous Silicon, (Ed.: L. Canham), INSPEC, London, 1997, p. 145.

[9] V. Lysenko, F. Bidault, S. Alekseev, V. Zaitsev, D. Barbier, C. Turpin, F. Geobaldo, P. Rivolo, E. Garrone, Study of Porous Silicon Nanostructures as Hydrogen Reservoirs, J. Phys. Chem. B 2005, 109, 19711-19718.

[10] R. C. Johnson, Silicon-based gunpowder may propel MEMS devices, EE TIMES 2002, 22 January.

[11] C. Sachdev, Chip provides more bang, Technology Research News 2002, 20 February.

[12] C. Becker, L. Currano, W. Churaman, Characterization and Improvements to Porous Silicon Processing for Nanoenergetics, Report ARL-TR-4717, U.S. Army Research Laboratory, Adelphi, MD, USA, 2009.

[13] P. Granitzer, K. Rumpf, Porous Silicon - A Versatile Host Material, Materials 2010, 3, 943998.

[14] A. Halimaoui, Porous Silicon Formation by Anodisation, in: Properties of Porous Silicon, (Ed.: L. Canham), INSPEC, London, 1997, p. 12.

[15] M. du Plessis, Properties of Porous Silicon NanoExplosive Devices, Sens. Actuators, A 2007, 135, 666-674.

[16] W. Churaman, L. Currano, A. K. Singh, U. S. Rai, M. Dubey, P. Amirtharaj, P. C. Ray, Understanding the high energetic behavior of nano-energetic porous silicon, Chem. Phys. Lett. 2008, 464, 198-201.

[17] A. Plummer, H. Cao, R. Dawson, R. Lowe, J. Shapter, N. H. Voelcker, The Influence of Pore Size and Oxidising Agent on the Energetic
Properties of Porous Silicon, Proc. SPIE 7267 2008, 72670P.

[18] B. A. Mason, S. F. Son, K. Y. Cho, R. A. Yetter, B. W. Asay, Combustion Performance of Porous Silicon-Based Energetic Composites, 45th AIAA/ASME/SAE/ASEE Joint Propulsion Conference, Denver, CO, USA, August 2-5, 2009 p. 5081.

[19] L. J. Currano, W. A. Churaman, Energetic Nanoporous Silicon Devices, J. Microelectromech. Syst. 2009, 18(4), 799-807.

[20] C. R. Becker, L. J. Currano, W. A. Churaman, C. R. Stoldt, Thermal Analysis of the Exothermic Reaction between Galvanic Porous Silicon and Sodium Perchlorate, Appl. Mater. Interfaces 2010, 2(11), 2998-3003.

[21] C. R. Becker, S. Apperson, C. J. Morris, S. Gangopadhyay, L. J. Currano, W. A. Churaman, C. R. Stoldt, Galvanic Porous Silicon Composites for High-Velocity Nanoenergetics, Nano Lett. 2011, 11, 803-807.

[22] S. Wang, R. Shen, Y. Ye, Y. Hu, An Investigation into the Fabrication and Combustion Performance of Porous Silicon Nanoenergetic Array Chips, Nanotechnology 2012, 23, 435701.

[23] D. Clément, J. Diener, E. Gross, N. Künzner, V. Yu. Timoshenko, D. Kovalev, Highly Explosive Nanosilicon-Based Composite Materials, Phys. Status Solidi A 2005, 202(8), 1357-1364.

[24] E. Fradkin, A. Gany, Investigation of Nanoporous Silicon-Based Energetic Materials, International Journal of Energetic Materials and Chemical Propulsion 2012, 11(2), 135-148.

[25] L. Clements, L. Puskar, M. J. Tobin, F. Harding, $\mathrm{H}$. Thissen, N. H. Voelcker, Preparation of Chemical Gradients on Porous Silicon by a Dip Coating Method, Proc. SPIE 7267 2008, 72670Q.

[26] W. Churaman, L. Currano, C. Becker, Initiation and Reaction Tuning of Nanoporous Energetic Silicon, J. Phys. Chem. Solids 2010, 71, 69-74.

[27] S. K. Lazaruk, A. V. Dolbik, V. A. Labunov, V. E. Borisenko, Combustion and Explosion of Nanostructured Silicon in Microsystem Devices, Semiconductors 2007, 41(9), 1113-1116.

[28] V. Lysenko, J. Vitiello, B. Remaki, D. Barbier, V. Skryshevsky, Nanoscale Morphology Dependent Hydrogen Coverage of Meso-Porous Silicon, Appl. Surf. Sci. 2004, 230, 425-430.

[29] Z. Li, X. Cheng, J.Wang, H. Chen, Theoretical Study of Interaction Between $\mathrm{S}_{2}$ and $\mathrm{SiH}_{\mathrm{x}}(\mathrm{x}=1$, 2, 3) in Porous Silicon, Chin. J. Chem. Phys. 2010, 23(3), 281-286. 
[30] S. Subramanian, T. Tiegs, S. Limaye, D. Kapoor, P. Redner, Nanoporous Silicon Based Energetic Materials, 26th Army Science Conference, Orlando, FL, USA, December 1-4, 2008, MP-08.

[31] E. C. Koch, D. Clément, Special Materials in Pyrotechnics: VI. Silicon - An Old Fuel with New Perspectives, Propellants, Explos., Pyrotech. 2007, 32(3), 205-212.

[32] R. Thiruvengadathan, G. M. Belarde, A. Bezmelnitsyn, M. Shub, W. Balas-Hummers, K. Gangopadhyay, S. Gangopadhyay, Combustion Characteristics of Silicon-Based Nanoenergetic Formulations with Reduced Electrostatic Discharge Sensitivity, Propellants, Explos., Pyrotech. 2012, 37, 359-372.

[33] S. K. Lazarouk, A. V. Dolbik, P. V. Jaguiro, V. A. Labunov, V. E. Borisenko, Fast Exothermic Processes in Porous Silicon, Semiconductors 2005, 39(8), 881-883.

[34] W. Churaman, L. Currano, M. Dubey, C. Becker, Fabrication and Characterization of Nanoporous Energetic Silicon, 26th Army Science Conference, Orlando, FL, USA, December 1-4, 2008, MP-03.

[35] M. du Plessis, C. Conradie, Nano-Explosions in Porous Silicon, Proc. SPIE 6037 2006, 60370X.

[36] R. Herino, G. Bomchil, K. Barla, C. Bertrand, J. L. Ginoux, Porosity and Pore Size Distributions of Porous Silicon Layers, J. Electrochem. Soc. 1987, 134(8), 1994-2000.

[37] M. du Plessis, Nanoporous Silicon Explosive Devices, Mater. Sci. Eng., B 2008, 147(2-3), 226229.

[38] S. Wang, R. Shen, Y. Ye, Y. Hu, An Investigation into the Fabrication and Combustion Performance of Porous Slicon Nanoenergetic Array Chips, Nanotechnology 2012, 23, 435701.

[39] W. A. Churaman, C. R. Becker, G. D. Metcalfe, B .M. Hanrahan, L. J. Currano, C. R. Stoldt, Optical Initiation of Nanoporous Energetic Silicon for Safing and Arming Technologies, Proc. SPIE 7795 2010, 779506.

[40] S. Wang, R. Shen, C. Yang, Y. Ye, Y. Hu, C. Li, Fabrication, Characterization, and Application in Nanoenergetic Materials of Uncracked Nano Porous Silicon Thick Films, Appl. Surf. Sci. 2013, 265, 4-9.

[41] C. J. Morris, K. E. Laflin, W. A. Churaman, C. R. Becker, L. J. Currano, D. H. Gracias, Initiation of Nanoporous Energetic Silicon by Optical Triggered, Residual Stress Powered Microactuators, IEEE 25th Intl. Conf. MEMS, Paris, France, January 29 - February 2, 2012, p. 1245.
[42] C. D. Malec, N. H. Voelcker, J. G. Shapter, A. V. Ellis, Carbon Nanotubes Initiate the Explosion of Porous Silicon, Mater. Lett. 2010, 64, 2517-2519.

[43] A. I. Manilov, V. A. Skryshevsky, Hydrogen in porous silicon - A review, Mater. Sci. Eng. $B$ 2013, 178, 942-955.

[44] L.Currano, W. Churaman, C. Becker, Nanoporous Silicon as a Bulk Energetic Material, Transducers 2009, Denver, CO, USA, June 21-25, 2009, p. 2172.

[45] B. A. Mason, K. Y. Cho, C. D. Yarrington, S. F. Son, J. Gesner, R. A. Yetter, B. W. Asay, SiliconBased Nanoenergetic Composites, 6th U.S. National Combustion Meeting, Ann Arbor, Michigan, USA, May 17-20, 2009, p. 2375.

[46] H. J. Fan, M. H. Kuok, S. C. Ng, R. Boukherroub, J.-M. Baribeau, J. W. Fraser, D. J. Lockwood, Brillouin spectroscopy of acoustic modes in porous silicon films, Phys. Rev. B 2002, 65, 165330(1-8).

[47] V. S. Parimi, S. A Tadigadapa, R. A Yetter, Control of Nanoenergetics through Organized Microstructures, J. Micromech. Microeng. 2012, 22, 055011.

[48] A. Plummer, V. Kuznetsov, T. Joyner, J. Shapter, N. H. Voelcker, The Burning Rate of Energetic Films of Nanostructured Porous Silicon, Small 2011, 7(23), 3392-3398.

[49] H. Föll, J. Carstensen, S. Frey, Porous and Nanoporous Semiconductors and Emerging Applications, J. Nanomater. 2006, 91635.

[50] W. A. Churaman, L. J. Currano, C. J. Morris, J. E. Rajkowski, S. Bergbreiter, The First Launch of an Autonomous Thrust-Driven Microrobot Using Nanoporous Energetic Silicon, J. Microelectromech. Syst. 2012, 21(1), 198-205. 